\title{
Won't you be my neighbor? Geography, peer learning, and entrepreneur performance in Togo
}

\author{
Stefan Dimitriadis \\ University of Toronto \\ stefan.dimitriadis@ rotman.utoronto.ca \\ Rembrand Koning \\ Harvard Business School \\ rkoning@hbs.edu
}

January 30, 2022

\begin{abstract}
Entrepreneurs, especially in developing economies, rely on peers for advice and managerial knowledge. While a growing body of work shows that introducing entrepreneurs to new peers outside their immediate neighborhood and social circles improves performance, these results are seemingly at odds with work on geographic spillovers which suggests that entrepreneurs are especially likely to learn and benefit from their neighbors. We explore these diverging predictions using data from a training program in Togo, during which entrepreneurs were randomly assigned to meet and talk to peers from across the city of Lomé. We find that meeting neighbors increases entrepreneurs' performance more than does meeting more distant peers. Profits increase by $10 \%$ when entrepreneurs get to know three neighbors who are on average $1 \mathrm{~km}$ closer. In additional analyses we find evidence that, in this context, entrepreneurs tend to be locally "under networked:" they are likelier to stay in touch with neighbors than with more distant peers and neighbors possess novel managerial knowledge. These results suggest that entrepreneurs in our context, and potentially in other developing economies, are often under networked, making neighbors particularly impactful for their performance.
\end{abstract}

Keywords: Entrepreneur performance, peers, geography, developing countries 


\section{Introduction}

Entrepreneurs rely on peers to access critical resources and knowledge, especially in developing economies. In the absence of formal managerial training, many entrepreneurs learn from the successes and failures of their peers (Chatterji et al. 2019, McKenzie 2021, Nanda and Khanna 2010). Similarly, in the absence of well-developed institutions, ranging from industry press to credit rating agencies, peers are an essential source of reliable and timely business information (Khanna 2018, Klüppel et al. 2018, Vissa and Chacar 2006).

Building on these arguments, researchers have increasingly used randomized control trials (RCTs) to explore the effect of peer learning on business performance in developing economies. These studies connect entrepreneurs with peers from outside their immediate social circles in the hopes of promoting the transfer of new practices and information (Anderson et al. 2020, Cai and Szeidl 2018, Fafchamps and Quinn 2018, Hasan and Koning 2019, Vega-Redondo et al. 2019). Often connecting entrepreneurs from across neighborhoods, cities, and countries, these studies largely show that entrepreneurs benefit from getting to know distant peers who can share novel knowledge and resources (McEvily and Zaheer 1999, Uzzi and Dunlap 2005, Wang 2015).

These arguments, however, appear to be at odds with research on geographic spillovers and the co-location of firms. In this view, entrepreneurs and firms face significant networking frictions and so neighbors, who are easier to discover and maintain relationships with, are especially valuable, accessible, and sustainable sources of advice (Catalini 2018, Dahlander and McFarland 2013). Moreover, agglomeration can magnify the value of being near and getting to know a neighbor by increasing the odds that neighbors have relevant and specialized business knowledge and resources (Alcácer and Chung 2014, Delgado et al. 2010, Rosenthal and Strange 2001). This view suggests that the effort and expense of connecting entrepreneurs with more distant peers may be unneeded. Instead, simply introducing entrepreneurs to their neighbors may be equally or even more effective at improving performance. Given the empirical evidence in favor of both the geographic spillover and peer learning views, it remains unclear what impacts entrepreneurial performance more: proximate or distant peers.

To test the relative value of getting to know a neighbor, we use data from a training program for entrepreneurs in Lomé - the largest city in Togo. During the program, entrepreneurs were randomized into meeting other small and medium business owners, who happened to be located near or far from them within Lomé. We couple the random assignment of peers with rich 
longitudinal data on firm performance to test the marginal value of getting to know one's neighbors versus peers from across the city.

We find that getting to know a neighbor-not a more distant peer — is especially valuable. On average, increasing the proximity between the focal entrepreneur and the three peers they were assigned by $1 \mathrm{~km}$ led to profit increases of about $10 \%$ over the next year. These results are robust to when we include fixed effects for time-invariant entrepreneur and neighborhood characteristics, as well a rich set of ego, alter, and ego-alter business characteristics that let us rule out a host of alternative peer effect mechanisms.

While consistent with work on geographic spillovers, the significant benefits of neighbors are puzzling given prior work on the value of more distant peers. From the perspective of the literature on peers, entrepreneurs tend to know people in their communities - they are well networked locally - and should, therefore, already know much of what their neighbors know, which is why getting to know another neighbor should be less useful. However, if we instead assume entrepreneurs are largely "under networked" to begin with, our findings are much less surprising. Without a strong local network, the risk of network redundancy diminishes and instead getting to know a neighbor will lead to stronger relationship formation, drive knowledge transfer that wouldn't occur otherwise, and so result in the performance improvements we observe.

To test this under-networked argument we analyze additional data on networking outcomes and managerial practices. Consistent with the idea that entrepreneurs are not already well networked locally, we find that getting to know a peer within $1 \mathrm{~km}$ versus a most distant peer leads to a substantial-20 percentage point - increase in the likelihood that contact is sustained in the year after the program, a $400 \%$ relative increase. While this finding echoes work randomizing entrepreneurs' location (Catalini 2018, Hasan and Koning 2019), our treatment is subtly but meaningfully different. We don't randomize entrepreneurs to have new neighbors, rather we introduce them to existing neighbors. That we find a substantial relationship formation effect suggests entrepreneurs were very much under-networked before the program.

Building on this evidence, we then turn to data on management practices to show that entrepreneurs' neighbors tend to possess non-redundant managerial knowledge, consistent with the idea that peer networks were not readily diffusing business knowledge within Lomé. Building on this descriptive evidence, we then check if being introduced to a neighbor improves the 
diffusion of valuable business knowledge. We find that entrepreneurs learn one additional management practice when assigned to peers who are on average $1 \mathrm{~km}$ closer.

Finally, we show that the relative value of getting to know a neighbor inverts for entrepreneurs who are better networked. We find that entrepreneurs who were already members of a local business association, a key driver of networking and peer learning (Zuckerman and Sgourev 2006), are actually more likely to benefit from getting to know a distant peer. However, only $10 \%$ of entrepreneurs in our sample are members of such associations, further solidifying the idea that the average entrepreneur in our setting is under-networked.

These findings make three primary contributions. First, they highlight that in developing economies there likely remains untapped value in one's neighbors. A growing body of researchoften relying on natural experiments and RCTs - shows that getting to know non-neighboring individuals from across a region, a country, or even the world can improve knowledge sharing and performance (Chatterji et al. 2019, Eesley and Wang 2017, Vega-Redondo et al. 2019). However, our results here suggest that it may not be necessary to span the globe. Instead, simply encouraging people to knock on their neighbors' doors or join a neighborhood association might be enough to promote knowledge transfer, relationship building, and performance improvements. At least in Togo, the knowledge shared between neighbors is far from redundant.

Second, our findings suggest that entrepreneurs' geographic strategy should not only consider where to locate, but also how to connect with others within that location. Existing research on "neighborhood effects" tends to emphasize location choice (Arzaghi and Henderson 2008, Chung and Alcácer 2002, Kalnins and Chung 2004), while often overlooking the interactions and socializing between entrepreneurs and their neighbors that can unlock additional gains from agglomeration, especially in developing countries. At a methodological level, measuring the relative value of getting to know a neighbor versus non-neighbor tells us both who entrepreneurs should prioritize to get to know and reveals whether entrepreneurs are well-networked or undernetworked within their local community. Relatedly, our results also suggest that analysts need to take care when considering the value of neighbors and neighborhoods. Indeed, as our moderation results show, getting to know a neighbor becomes less vital when an entrepreneur is especially connected to the neighborhood.

Finally, this study helps extend work on advice and networks to developing economy contexts. This literature often emphasizes the value of peers located further away. Yet, it tends to 
assume that entrepreneurs are already "plugged into" their local networks and thus well networked. Results from this study suggest that this assumption may be inappropriate in developing economy contexts, where factors such as ethnic and gender divisions, poor infrastructure, and institutional voids (Khanna and Palepu 2010, Klüppel et al. 2018, Yenkey 2015) make it so that many neighbors are, in fact, network "outsiders" and possess valuable knowledge.

\section{The spatial proximity of peers and entrepreneur performance}

Entrepreneurs rely on peers for a variety of critical information about suppliers and clients, better business practices, and new government policies (Ingram and Roberts 2000, Vissa and Chacar 2009). Beyond information, peers are also important sources of financing (Hallen and Eisenhardt 2012, Shane and Cable 2002) and social support (Zuckerman and Sgourev 2006). The impact of

peers is particularly critical in the context of developing economies, where entrepreneurs typically have less access to formal sources of financing, training, and reliable market information (Dimitriadis 2021, Fafchamps 2006, Khanna 2018, Klüppel et al. 2018).

The performance effects of peers in developing economies has been increasingly explored through RCTs, which match entrepreneurs with peers from across regions (Cai and Szeidl 2018), countries (Chatterji et al. 2019, Fafchamps and Quinn 2018), and internationally (Anderson et al. 2020, Vega-Redondo et al. 2019). These experimental studies have helped establish a causal link between learning from peers outside entrepreneurs' regular social circles and improvements in performance.

These studies are based on a theoretical argument that bringing people together, especially across geographic regions, can promote the transmission of novel knowledge and resources (Granovetter 1973, Wang 2015). This perspective emphasizes that distant peers have an advantage in providing access to novel information and knowledge because they are less likely to share direct or indirect network connections with the focal entrepreneur, which makes it likelier that the focal entrepreneur has not already encountered the information they possess (Bell and Zaheer 2007, McEvily and Zaheer 1999). As a result, meeting a distant peer might expose entrepreneurs to new products, processes, or practices, which local peers are not familiar with. This novelty can enable entrepreneurs to innovate, improve their managerial practices, and find new clients (Ahuja 2000, Hargadon and Sutton 1997, Rosenkopf and Almeida 2003). All of which should lead to improvements in performance. 
Although there is considerable empirical evidence for this perspective, research on geographic spillovers and the co-location of entrepreneurs offers seemingly contradictory insights. According to the geographic perspective, it may be more valuable to get to know neighbors, rather than more distant peers. In particular, more proximate entrepreneurs may be easier to form relationships with, since proximity increases the odds of repeated interactions (Catalini 2018, Dahlander and McFarland 2013, Small and Adler 2019). These frequent interactions also enable the exchange of more information and the acquisition of more complex knowledge (Arzaghi and Henderson 2008, Kerr and Kominers 2015, Whittington et al. 2009). By observing and interacting with local peers, entrepreneurs are likely to learn from them (Chan et al. 2014). This effect may be particularly important for entrepreneurs when they are located in clusters where there exists specialized knowledge and skilled labor pools (Alcácer and Chung 2014, Chauvin 2019, Delgado et al. 2010, Rosenthal and Strange 2001). In these locations, local peers may help entrepreneurs tap into these local, specialized resources and knowledge (Almeida and Kogut 1999, Sorenson and Audia 2000). This literature, as a result, suggests that neighbors, not distant peers, are valuable for entrepreneurs.

Importantly, the geographic spillover view suggests that entrepreneurs perhaps shouldn't invest the time and effort needed to get to know more distant peers. Rather, they should simply reach out to neighbors. Given that networking is a time consuming and effortful process (Casciaro et al. 2014, Kuwabara et al. 2018), which becomes more effortful for distant peers, exploring which theoretical perspective is more relevant could have important implications for entrepreneurs' networking practices. It, moreover, could also have implications for how organizations, such as incubators or training programs, design networking events.

\section{Research setting: Entrepreneur training program in Lomé, Togo}

To study the relative effect of meeting proximate peers compared to more distant ones, we used data from a training program for entrepreneurs in Lomé, Togo. Situated between Ghana and Benin, Togo is a developing economy that is representative of many sub-Saharan markets in terms of its formal institutions and infrastructure (United Nations Development Programme 2017, World Bank 2016). With a population of approximately 2 million, Lomé is the capital of Togo and host to a rapidly growing and diverse entrepreneurial ecosystem that is widely dispersed across the city (US Embassy in Togo 2019). 
Within this context, we took advantage of a networking event during an entrepreneurship training program. ${ }^{1}$ This setting was ideal because it brought together a large number of entrepreneurs from different parts of the city, creating the opportunity for entrepreneurs to meet peers from their own neighborhood and elsewhere. The criteria for entrepreneurs to participate in the training program was that their businesses must have been in operation for at least one year and that it be located within the city. The program consisted of 14 cohorts of 20-25 entrepreneurs and the training covered marketing practices and social skills over the course of two days during April and May 2017. Each cohort was trained separately, hence the training program occurred over approximately six weeks. In total, 303 entrepreneurs completed the training. The training program followed the well-established International Labor Organization's "Start and improve your business" program. The training was conducted by two Togolese instructors, who were management consultants from Lomé, each with decades of experience teaching local entrepreneurs.

At the end of the training program, when all the lectures had been completed, entrepreneurs participated in a "structured" networking event. During this event, entrepreneurs were randomly assigned to have successive one-on-one conversations with three discussion partners from within their cohort. The randomization of discussion partners was done by one of the authors who was present during the training program. For each one-on-one discussion, participants were paired with other participants through random draws. Participants were given 30-45 minutes for each of the conversations. The two instructors managed the structured network event, making sure that participants met with their assigned peers and switched to their next assigned peer at the right time. The networking event's format therefore resembled a slow-paced "speed dating" event.

\section{Research design}

It is difficult to identify the effect of social interactions on entrepreneurial performance because most interactions are highly endogenous (Hasan and Bagde 2013, Manski 1993). Interactions can be driven by unobserved entrepreneur characteristics related to their performance, such as their

\footnotetext{
${ }^{1}$ Data from this training program were previously used in a separate study of entrepreneur training. However, that study did not use any of the networking data used in the present study or the randomization we rely on for identification. We do rely on the same pre- and post-training program surveys that measure performance, management practices, and relationship formation. The present study was not pre-registered as a field experiment and the randomization is therefore more akin to a "natural" experiment.
} 
ability or status, and hence it becomes difficult to separate how much of their performance is due to their ability and how much due to the interactions they have. Similarly, dyad characteristics can also confound the effect, certain pairs may be likelier to interact than others and hence it is difficult to distinguish whether an interaction was impactful or whether high performing entrepreneurs are likelier to interact with each other. Following recent studies on entrepreneur peer relationships (Chatterji et al. 2019, Hasan and Koning 2019), we take advantage of the randomization of discussion partners during the networking event to overcome these identification challenges.

By randomizing entrepreneurs' three discussion partners we introduce exogenous variation in who entrepreneurs talk to during the networking event. Interactions are not driven by ability or preferences, rather they are randomly assigned. Given that entrepreneurs' location is fixed before their attendance at the program and that each training cohort included entrepreneurs from a variety of different parts of the city, the randomization also introduced exogenous variation in the extent to which entrepreneurs talked to proximate or more distant peers during the networking event. Further, in contrast to naturally occurring peer variation, which often relies on variation in large cohorts of dozens of people (Angrist and Lang 2004, Fafchamps and Quinn 2018, Lerner and Malmendier 2013), the fact that in our setting participants were randomized into only three conversations ensures wide variability in our treatment, with some entrepreneurs getting to know a few neighbors and none at all. If instead peers had been assigned to have conversations with 10 peers, statistically there would be substantially less variation in how near or far they were on average from their assigned peers.

Indeed, in Figure 1 we show visual evidence that our randomization leads to substantial variation in how close a participant's randomly assigned conversation partners were. The figure shows the approximate location of each entrepreneur in our sample on a map of Lomé. The color of each marker reflects the extent to which that entrepreneur was assigned to peers who were near or far. Blue colors indicate that peers were nearby, while red colors indicate the entrepreneur was assigned to discussion peers who were farther away. The map shows that, even within neighborhoods there is substantial variation in whether an entrepreneur got to know neighbors or more distant peers, both in terms of how far the closest peer was (Panel A) and in terms of average proximity (Panel B). In Appendix A2 we also present balance tables showing that the treatmentthe average proximity to the randomly assigned peers-is unrelated to entrepreneurs' pretreatment characteristics. That said, below we discuss how we use our longitudinal data along with 
inverse propensity score weighting to fully account for the fact that entrepreneurs in denser neighborhoods, who may well be higher or lower performing on average, appear more likely to be assigned to nearby peers.

*** Insert Figure 1 about here ***

\section{Data and variables}

A baseline survey collected data about entrepreneurs and their performance before the training program. After the networking event we scanned participants' handwritten notes from their oneon-one discussions and administered an exit survey with questions about their interactions during the event. Finally, we collected data on the impact of the networking event during three follow-up surveys. The first follow-up survey took place six weeks after the training program, the second six months after it, and the third one year after it.

The exit survey and the follow-up surveys after the training program were conducted by the same instructors who taught the training program. To lower attrition rates the instructors offered entrepreneurs advice about their businesses after each survey was completed. The attrition rate over all surveys was $8 \%$, which is relatively low compared to other studies of entrepreneurs in developing economies (McKenzie and Woodruff 2014).

\subsection{Dependent variables}

Our outcome of interest is entrepreneur performance. We use two measures of performance common in research on firms in developing economies, where measuring profits can be challenging. Our first measure is monthly profits (log). The surveyors, who had established a relationship with the participants, asked for entrepreneurs' estimated profits from the previous month. To increase the precision of entrepreneurs' reported profits the surveyors also asked them to estimate monthly expenses and sales, which helped triangulate their profits. This approach has been shown to be relatively successful at gaining an accurate impression of business performance in developing economies (De Mel et al. 2009, Fafchamps et al. 2012).

Our second measure of performance was a performance index. This is the average of several standardized variables that are indicative of performance. In particular, we took the mean of $\log$ monthly profits, log monthly profits winsorized at the 1st and 99th percentiles, log profits 
last week, log sales last month, log sales last week, and log clients last month. This approach helps combine many different measures that are related to performance and reduces concerns of measurement error (Campos et al. 2017, Kling et al. 2007).

\subsection{Independent variables}

The main independent variable is average proximity to discussion peers. This measures the average proximity of the focal entrepreneur to their three assigned discussion partners. Using the geographic coordinates of entrepreneurs' businesses, we calculate the straight-line distance in kilometers between each dyad of participants. We then use this distance to create a measure of proximity using an exponential distance decay function. Following standard practice in economic geography (De Vries et al. 2009, Pun-Cheng 2016), we generate a proximity measure using the following equation:

$$
p_{i j}=e^{-0.1 d_{i j}}
$$

Where $d_{i j}$ is the distance between focal entrepreneur $i$ and discussion partner entrepreneur $j$. Hence, $p_{i j}$ measures the proximity of entrepreneur $i$ to entrepreneur $j$, and ranges from 1 for peers located at a distance of $0 \mathrm{~km}$ and tends towards 0 as the distance increases. This approach models the effect of proximity as decaying exponentially, rather than linearly. Indeed, a large body of work shows that proximity decays exponentially and not linearly in social interactions (Barthélemy 2011, Fotheringham 1981). Although we believe this decay function is the most appropriate for our data, in Appendix A5 we estimate our performance results using two alternative decay functions, showing that our results are not dependent on this particular specification.

To create a single measure for each entrepreneur we take the average of the proximities of the three assigned discussion peers:

$$
P_{i}=\frac{1}{3} \sum_{j=1}^{3} p_{i j}
$$

The average proximity, $P_{i}$, is our main measure for testing the effect of discussions with more proximate peers compared to more distant ones.

In addition to our average proximity measure, we also use a set of measures of proximity based on radii around each entrepreneur. In particular, we count the number of discussion peers located within a given radius of each entrepreneur. We construct this measure for radii of 1, 2, 3, 4,5 , and $6 \mathrm{~km}$ around each entrepreneur. This measure of proximity to peers does not account for 
the exponentially decaying effect of distance, but it is a simple non-parametric measure that lends itself to easy interpretation (Conley 2011).

In addition to our main independent variable of interest we also include two control variables that are important because of the structure of the empirical setting. First, we control for whether the entrepreneur received training in social skills. Although the training program taught all participants marketing skills, it only taught half the cohorts social skills. Hence, to ensure that our results are not driven by the social skills training that some participants received, we controlled for whether the entrepreneur received social skills training. ${ }^{2}$ Second, we control for the number of discussion partners entrepreneurs knew from before the training program. Occasionally some participants found that they already knew their peers. We gave each participant a roster of their cohorts and asked them to identify any co-participants they had met before. Using this information, we counted the number of discussion partners entrepreneurs happened to already know and included it as a control variable.

We report the summary statistics in Table 1 . The average entrepreneur generated monthly profits of 56,500 Francs CFA (approximately \$95 USD). The median entrepreneur did not know any of their discussion peers before the training. Half of the entrepreneurs received the social skills training during the program. The majority of entrepreneurs were part of the Ewe ethnic group, male, and had completed primary school. Their businesses, on average, had two employees, had been in operation for approximately 10 years, and used $60 \%$ of managerial best practices that are part of the McKenzie and Woodruff (2018) index. Correlation tables and additional descriptive statistics for the dyad-level data are presented in Appendix A1.

*** Insert Table 1 about here***

\section{Estimation strategy}

To assess the effect of peer proximity on entrepreneur performance we use a difference-indifferences estimation approach. Our baseline survey measures performance before the training program when discussion peers were assigned, while our three follow-up surveys measure changes

\footnotetext{
${ }^{2}$ In this study we do not explore interaction effects between the social skills training and the average proximity of assigned peers largely because the sample size is not large enough to accurately estimate those interactions. Nevertheless, we ran these regressions and did not find any statistically or substantively significant interaction effects.
} 
in performance after the training program. This empirical approach compares how the performance of entrepreneurs who were assigned to more proximate peers changed relative to how the of entrepreneurs who were assigned to less proximate peers changed. The model we estimate is:

$$
Y_{i t}=\beta\left(P_{i} \times \text { PostTraining }\right)+\gamma\left(X_{i} \times \text { PostTraining }\right)+\alpha_{i}+\delta_{t}+\varepsilon_{i t}
$$

Where $Y_{i t}$ is logged monthly profits for entrepreneur $i$ in the month prior to survey $t$. As described above, $\mathrm{P}_{\mathrm{i}}$ is the average proximity of assigned discussion peers. PostTraining is a dummy variable equal to 1 for time periods after the training program and 0 for the baseline period. $X_{i}$ is a vector of our two control variables, social skills training and number of discussion partners known from before. Both of these control variables are time invariant and thus absorbed by the fixed effects.

However, to account for the fact that these variables might have a time-varying effect we interact each with the PostTraining time indicator ${ }^{3} . \alpha_{i}$ are entrepreneur fixed effects that control for time-invariant differences between entrepreneurs. $\delta_{t}$ are survey wave fixed effects that control for time trend effects, such as general economic conditions in Lomé. All our regressions of this model cluster standard errors at the neighborhood level letting observations be independent across neighborhoods but not across participants in the same neighborhood.

As briefly mentioned above, including entrepreneur fixed effects in the model is important because they control for differences in the kinds of neighborhoods that entrepreneurs are located in, which is likely related to the number local peers they are assigned and their performance. In particular, entrepreneurs in crowded neighborhoods are more belikely to be assigned neighboring discussion peers simply because there are more of them, but are also likely to operate in more competitive environments that might lower their performance (or vice versa if denser neighborhoods give better access to customers). In this example, the probability of treatment (i.e., talking with a neighbor) ends up correlated with underlying business performance. However, given that entrepreneurs' neighborhoods are fixed and do not shift during our one-year study, entrepreneur fixed effects will account for all such differences.

\footnotetext{
${ }^{3}$ In Appendix A11 we estimate these models without these two control variables and the results remain unchanged, both in terms of statistical significance and the magnitude of the coefficients. We also present models which add other entrepreneur and peer controls. We find that these also do not affect the magnitude or statistical significance of our results.
} 
Unfortunately, while fixed effects can remove selection bias, they can also introduce their own bias because of the way models with fixed effects weight and average the underlying within effects (Declare Design 2018, Gibbons et al. 2019). A simplified example is helpful to see why. Instead of continuously varying locations, imagine we had 200 entrepreneurs from only two neighborhoods. Neighborhood A is dense so for these firms the probability of treatment $p$, in our case meeting a neighbor, is 0.5 ; for firms from neighborhood $\mathrm{B}$ the probability of meeting a neighbor is only $p=0.2$. Since entrepreneurs in A are closer to more neighbors they might benefit less from an introduction, so assume a treatment effect on performance of 5\% for these firms. For $\mathrm{B}$, assume a larger treatment effect of $35 \%$. The overall average treatment effect (ATE) is simply the sample size weighted average across these groups, $(5 \% \times 100+35 \% \times 100) / 200=20 \%$. However, if we instead estimated the treatment effect by running a regression with neighborhood fixed effects each neighborhood would be weighted not by the sample size but by the sample size multiplied by the variance of the treatment assignment probability, which in our case is simply p*(1-p) (Declare Design 2018). In our example the fixed effects estimate yields a much smaller effect size of only $(5 \% \times 100 \times 0.5 \times 0.5+35 \% \times 100 \times 0.2 \times 0.2) /(100 \times 0.5 \times 0.5+100 \times 0.2 \times$ $0.2)=9.1 \%$. This fixed effect estimate is less than half the true average treatment effect.

Fortunately, when analyzing experiments, inverse propensity weights (IPW) can be used to fully address this weighting-induced fixed effect bias. Since we know the exact assignment procedure we can calculate the actual probability of assignment, and so the inverse propensity weight, for each observation. This is in contrast to observational studies where researchers often construct estimated IPWs to account for selection bias and risk that the resulting estimated effects may still be biased if the model used to estimate propensity score is misspecified.

To account for this "weighting" bias we include IPWs in all our models along with the aforementioned entrepreneur fixed effects. Given our core treatment variable is a continuous measure of proximity to the three randomly assigned peers we build continuous inverse probability weights. Since entrepreneurs are assigned to three randomly assigned peers within each cohort of our training program, we calculate propensities relative to the set of other entrepreneurs they could have been assigned to in their cohort. In models where we use dichotomous treatment measures 
(e.g. assigned to a peer within $1 \mathrm{~km}$ ) we calculate standard IPWs using differences in the expected probability of being assignment to a peer within the radius or not ${ }^{4}$.

Finally, it is worth noting that Equation (3) does not include additional control variables that might vary post-treatment (for example, we do not control for entrepreneurs' management practices or firm size) to avoid biasing our estimates (Acharya et al. 2016). When treatments are randomized - in this case peer assignment-conditioning on post-treatment covariates can unbalance the treatment and control groups, making treatment estimates biased and inconsistent (Montgomery et al. 2018). As a result, we do not include time varying controls that could also be influenced by the treatment and simultaneously influence the outcome variable. The two control variables we do include — social skills and the number of peer connections-are both measured pre-treatment and so the values cannot be the result of our treatment. Instead, these variables capture differences in the pre-treatment trajectories, not in post-treatment outcomes.

\section{Results}

Table 2 presents regressions testing whether spatial proximity to randomly assigned peers affects the performance of entrepreneurs. All regressions in Table 2 estimate equation (3). In Models 1-5 the outcome is monthly profits (log), while in Model 6 the outcome is the performance index.

Model 1 estimates the effect of average peer proximity on entrepreneurs' logged monthly profits, where average proximity is measured using the exponential decay function described in equations (1) and (2). According to the results in Model 1, a one standard deviation increase in the proximity of peers leads to an approximately $10 \%$ increase in monthly profits. ${ }^{5}$ The standard deviation in this case is equivalent to approximately $1 \mathrm{~km}$. The results therefore suggest that when the average proximity of the three assigned peers increases by $1 \mathrm{~km}$, this leads to a performance increase of $10 \%$.

*** Insert Table 2 about here ***

\footnotetext{
${ }^{4}$ In Appendix A3 we show that our performance results still hold when we exclude IPWs and are therefore not contingent on including these in our model.

${ }^{5}$ Because average proximity is calculated using an exponential function, these effect sizes will be larger at closer distances and smaller at larger distances from the focal entrepreneur. In other words, increasing average proximity by $1 \mathrm{~km}$ leads to $13 \%$ increase in profits when the peers are about $2 \mathrm{~km}$ away, but would likely lead to much smaller increases when the peers are say $30 \mathrm{~km}$ away (i.e. increasing proximity from 30 to $29 \mathrm{~km}$ does not lead to a $13 \%$ boost in profits, it would be less, likely around 2-3\%.).
} 
We plot these performance effects in Figure $2 .{ }^{6}$ The dashed grey line shows the average predicted $\log$ monthly profits at each given survey wave for entrepreneurs whose assigned peers were 1 standard deviation above the mean in average proximity. The solid black line shows the predicted $\log$ monthly profits for entrepreneurs whose discussion peers who were 1 standard deviation below the mean in average proximity. The average performance for entrepreneurs with peers who are more proximate is higher than that entrepreneurs whose peers are further away beginning six weeks after the training. Figure 2 shows that networking with neighbors does not have an immediate impact on profits. Rather, performance differences become statistically significant after six weeks. This aligns with our analysis, presented in the following section, that the value of neighbors is tied to the fact that entrepreneurs can better sustain relationships with neighbors. Finally, Figure 2 also illustrates that entrepreneurs assigned more distant peers may also experience increases in performance, although these are smaller and occur later. Hence, networking with distant peers isn't necessarily bad, rather it produces smaller returns than networking with neighbors.

\section{*** Insert Figure 2 about here $* * *$}

Models 2-5 in Table 2 rely on a different approach to measuring peer proximity. As described earlier, this approach uses the number of discussion peers within a given radius around the focal entrepreneur. Model 2 uses a radius of $1 \mathrm{~km}$ and estimates the impact on profits of being assigned an additional discussion peer located within $1 \mathrm{~km}$. Coefficient estimates suggest that, on average, being assigned another peer that is $1 \mathrm{~km}$ or nearer increases profits by approximately $30 \%$ with a confidence interval from $12 \%$ to $55 \%$. Similarly, being assigned an additional peer within $2 \mathrm{~km}$ of leads on average to an increase of approximately $20 \%$ and being assigned a peer within $3 \mathrm{~km}$ leads to an approximately $10 \%$ increase in performance.

By construction, these measures of proximity based on radii tend to overstate the impact of proximity on performance because in each case the reference group are entrepreneurs who were assigned a peer anywhere outside that radius. In other words, the performance effect of being assigned a peer less than $1 \mathrm{~km}$ away is compared to the performance effect of a peer from any other location across the city further than $1 \mathrm{~km}$ away. This comparison tends to stack the odds in

\footnotetext{
${ }^{6}$ The regressions used for Figure 2 are shown in Appendix A6.
} 
favor of finding a large effect for peers who are within $1 \mathrm{~km}$, since they are being compared to peers in a variety of locations which we might not expect to have a meaningful relevance to the focal entrepreneur.

These radial measures of proximity are instead meant to be compared against each other. On its own the coefficient for being assigned a peer within $1 \mathrm{~km}$ tells us relatively little. But when compared to the impact of being assigned a peer within $2 \mathrm{~km}$, it conveys much more. Using this approach, we see that being assigned a peer within $1 \mathrm{~km}$ increases performance by nearly $10 \%$ compared to being assigned a peer within $2 \mathrm{~km}$. Similarly, being assigned a peer within $2 \mathrm{~km}$, rather than $3 \mathrm{~km}$, increases the performance impact of that peer by about $8 \%$. The pattern that emerges from these coefficients is that increasing the proximity of assigned peers increases their impact on performance, which is consistent with the effect estimated using the continuous measure of proximity.

Another way of gaining the same insight involves plotting these coefficients, as shown in Figure 3, which also includes coefficients for radii of $5 \mathrm{~km}$ and $6 \mathrm{~km}$. The plotted coefficient estimates show that as the distance from the focal entrepreneur increases, the effect of the neighboring peers decrease. It is important to note that since all entrepreneurs received the same number of discussion peers, the reference group in these models is not "not receiving a peer" but rather "receiving a peer outside the radius." Hence, the models do not suggest that meeting an additional peer is not valuable when they are 4 or more kilometers away, but rather that the difference between them being inside the radius or not is no longer significant. Moreover, as we describe in Appendix A13, at distances of $4 \mathrm{~km}$ or more the proportion of entrepreneurs not treated decreases, reducing our statistical power to detect effects, which suggests that we may also be underpowered to detect small performance effects at larger distances.

*** Insert Figure 3 about here $* * *$

Finally, Table 2 also estimates the effect of average peer proximity on the performance index in Model 6. The performance index is an alternative approach to measuring entrepreneur performance that helps mitigate concerns related to measurement error and outlier observations (Kling et al. 2007). The results from Model 6 suggest very similar performance effects from meeting more 
proximate peers. The coefficient is positive and statistically significant, and is approximately the same size in magnitude as the coefficient in Model 1.

In Appendix A10 we replicate these performance results using dyad-level data. In those regressions the unit of observation is the entrepreneur-peer match and we regress the focal entrepreneurs' performance on their distance from each assigned peer, including ego, alter, and dyad fixed effects. Including dyad level fixed effects ensures that the entrepreneur-peer match quality isn't driving the performance effect, but rather the distance between them is.

\section{Why are neighbors more valuable? Entrepreneurs are locally under-networked}

Our analyses reveal that meeting a neighbor increases entrepreneurs' performance more than meeting a peer located further away. Although this result aligns with research on geographic spillovers and firm co-location, it seems to go against research on peer learning, which emphasizes the value of more distant peers. This peer learning literature argues that more distant peers are valuable because they are likely to share fewer mutual ties with the focal entrepreneur and therefore are likelier to provide novel information and knowledge, which tend to improve entrepreneurs' performance.

An underlying assumption in this peer learning perspective is that entrepreneurs tend to be

locally well networked. In other words, they are likely to know other peers near them, have exchanged information with them and their mutual contacts, and been exposed to a lot of the same information that their peers have. This implies a state of the world where meeting another local peer is likely to lead to redundant information and knowledge. If we relax this assumption, however, and instead allow entrepreneurs to be under-networked, then neighbors may be just as valuable, or more, than distant peers. If entrepreneurs tend not to know their local peers, then their neighbors' knowledge is not likely to be redundant, making the introduction particularly valuable.

In developing economies, such as Togo, institutional conditions are such that many entrepreneurs are likely to be under networked. These contexts often a lack organizations that facilitate networking (Armanios et al. 2017). Ethnic fractionalization can also create divisions between ethnically diverse neighborhoods (Hjort 2014, Yenkey 2015). Moreover, entrepreneurs may hesitate to interact with neighbors because they have limited legal protections in case of fraud or theft (Khanna and Palepu 2010, Klüppel et al. 2018). As a result, entrepreneurs might not be aware of local peers and, if they are, may believe that interacting with them is risky. Under these 
circumstances, it may be likely that the average entrepreneur is under networked. This, in turn, might explain why introductions to neighbors are more valuable than to distant peers.

To gain quantitative insight into whether this under-networked argument explains the benefits of meeting local peers we conduct three sets of analyses. First, if entrepreneurs are indeed under networked, they should be particularly likely to stay in touch with any neighbors introduced to them, because those neighbors would not be redundant contacts in the context of their local community. Second, if entrepreneurs are under networked, their managerial practices should not generally resemble those of their neighbors. Instead, neighbors should know different practices, which entrepreneurs then learn from them. Third, if meeting neighbors is valuable because entrepreneurs tend not to know their neighbors, then we should not observe this effect for entrepreneurs who happen to be well networked in their neighborhoods.

To conduct these tests we use additional variables, described here:

Local association member captures whether the entrepreneur was a member in one or more local associations. During each survey, entrepreneurs were asked whether they were members of various common types of associations, including civic, non-governmental, professional, religious, sports, and more, and whether those associations were local, which meant that the majority of members were from the entrepreneurs' neighborhood.

Years in neighborhood is a count of the number of years the entrepreneurs' business has been located in its current neighborhood.

Peer known from before is a dyad-level indicator of whether an entrepreneur knew a peer in their training program cohort from before the training. Each entrepreneur was given a roster of their co-participants and asked to indicate whether they knew any of their peers before attending.

Similarity in management practices is a dyad level measure of the similarity between each entrepreneurs' management practices and their peers'. For each dyad it was calculated as the Euclidean distance between the vector of marketing, planning, stocking, and financial management practices used by the focal entrepreneur and each of their peers, multiplied by -1 .

Management practices score is the proportion of 27 managerial best practices, defined by McKenzie and Woodruff (2018) as being closely correlated to performance, that the entrepreneur uses. The practices cover marketing, finance, planning, and stock management.

Tie formation is a dyad-level indicator of whether an entrepreneur kept in touch with their assigned discussion partner after the training program. During each follow-up survey after the 
training program entrepreneurs were asked to name any of the other entrepreneurs from the training they had spoken to over the phone or met with in person over the past six months.

\subsection{Meeting neighbors is more sustaining}

If entrepreneurs tend not to know their neighbors, then we would expect introductions to neighbors to be particularly likely to lead to the formation of a relationship. On the one hand, this introduction would represent an opportunity for the under-networked entrepreneur to tap into local resources and knowledge. On the other hand, it would not be a redundant contact because the undernetworked entrepreneur would not have alternative means of accessing the knowledge and resources that this newly introduced neighbor possesses. In contrast, if entrepreneurs are well networked and tend to know their neighbors, then meeting a new neighbor might not be likely to lead to a relationship, since the entrepreneur already has access to local resources and isn't reliant on the new acquaintance to access others in the neighborhood.

To assess whether this is the case, we estimated the impact of proximity between assigned peers on whether they were likely to form and sustain a relationship. Using data from the followup surveys, we regressed relationship formation on proximity using OLS models with entrepreneur fixed effects, partner fixed effects, and survey wave fixed effects. We also clustered standard errors at the ego, alter, and dyad levels (Kleinbaum et al. 2013). Proximity was measured at the dyad level, between each pair of entrepreneurs who were assigned to talk to each other, and was calculated using Equation 1. These analyses contain only three time periods, those after the training, because the formation of a tie could only be observed in those periods.

Table 3 shows the regression results. In Model 1, the coefficient for proximity is positive and statistically significant, indicating that the closer two discussion partners are located the more likely it is they will form a relationship after the training. Models 2-5 in Table 3 estimate the effect of assigned peers being within different radii of the focal entrepreneur on the likelihood of forming a tie. The coefficients gradually decrease in magnitude as the radii increase, suggesting that the likelihood of forming a tie decreases as the distance between them increases. The coefficients from these regressions are plotted in Figure 5, to provide a visual representation of the declining probability of tie formation. The effects are meaningful and large. Being assigned to a peer within $1 \mathrm{~km}$ increases the likelihood of building and sustaining a relationship with them by 20 percentage points over the next year. In relative terms, entrepreneurs are $400 \%$ more likely to build and sustain relationships with their neighbors. 
$* * *$ Table 3 about here $* * *$

*** Insert Figure 5 about here ***

Furthermore, the fact that we find large effects on relationship formation with neighbors helps potentially explain the relatively large performance effects we find. Entrepreneurs who were matched with a distant peer were likely to only have one conversation with them according our models. In contrast, entrepreneurs matched with neighbors were significantly more likely to stay in touch and have repeated interactions over the next year. Put differently, the large effect of meeting a peer isn't merely the result of information transmitted during the initial conversation, but is the result of advice exchanged during repeated interactions over the next year. This is consistent with research showing that peer effects involving interactions over the course of a year lead to large performance effects (Cai and Szeidl 2018).

\subsection{Meeting neighbors leads to learning more management practices}

If the benefit of meeting neighbors is driven by the fact that entrepreneurs are under networked, we should also observe that neighbors possess non-redundant knowledge. In particular, neighbors should know management practices the focal entrepreneur does not and as a result physical proximity should not be predictive of having the same management practices.

Using our measure of management practices similarity, we show that proximity is not related to similarity in management practices in a statistically significant way. Instead, we find that neighbors often possess managerial knowledge that is novel to the focal entrepreneur. Table A9.1 in the Appendix A9 regresses the similarity between the focal entrepreneurs' management practices and the practices of each of their peers in the training program on their physical proximity. The table shows that proximity is not correlated with the novelty of managerial knowledge that peers possess in a uniform way. While planning and financial management practices are more similar among neighbors, this isn't the case for other management practices.

Further, our data also allows us to test whether entrepreneurs actually learn managerial practices from their neighbors. To do so, we estimate the impact of meeting a more proximate peer on changes in entrepreneurs' management practices. We used the same difference-in-differences estimation approach as in Equation 3, but replace the outcome variable with entrepreneurs' 
management practices score. Results of regressing management practices on average peer proximity are shown in Table 4 . The coefficient for average peer proximity in Model 1 is positive and statistically significant. The magnitude of the coefficient suggests that on average a one standard deviation increase in proximity (about $1 \mathrm{~km}$ ) is associated with a $4 \%$ increase in entrepreneurs' management score, or the equivalent of one new management practice. Figure 6 provides graphical evidence of the impact of meeting neighbors on management practices. It shows the average predicted management practices score for entrepreneurs who were assigned peers one standard deviation above or below the mean in terms of their proximity. According to the figure, after six weeks the two groups diverge in terms of their learning and the changes in their management practices, with those entrepreneurs with more proximate peers improving more over time.

*** Insert Table 4 about here $* * *$

$* * *$ Insert Figure $6 * * *$

Models 2-5 measure the effect of proximity using radii. The pattern emerging from these models is that, as we would expect, the effect of peers on management practices diminishes as the distance from them increases.

\subsection{Well networked entrepreneurs do not benefit from meeting neighbors}

If being locally under networked explains the performance effects we observe, we should see the impact of meeting neighbors decrease or even reverse for entrepreneurs who are not under networked. To test this we use two indicators that proxy for the extent to which entrepreneurs know others locally. Our first indicator is membership in local associations (Putnam 2000, Ruef and Kwon 2016). Only about $10 \%$ of entrepreneurs in our sample were members of one or more local associations. ${ }^{7}$ We expect that entrepreneurs who are members of such associations tend to know people in their neighborhoods and are therefore not under networked. These entrepreneurs should not benefit much from meeting another neighbor. Results in Table 5 show that for

\footnotetext{
${ }^{7}$ The 2016 Afrobarometer survey of Togo reported that only $16 \%$ of all respondents to their national survey participated in voluntary associations or community groups, which is a little higher than the rate of participation among entrepreneurs in our sample.
} 
entrepreneurs who were members of a local association meeting a distant peer was more valuable than meeting a neighbor. In Models 1 and 2, the three-way interaction term is negative and statistically significant, suggesting that for entrepreneurs who participate in local associations the value of a new acquaintance decreases the closer they are located to them. All models in Table 5 include the controls for social skills training and peers known from before, as well as continuous IPW.

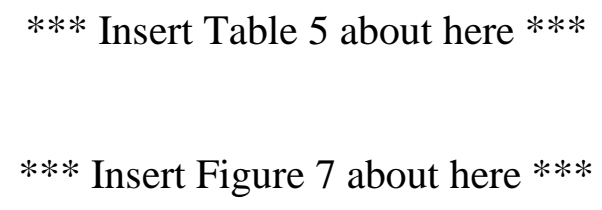

In supplementary analyses, presented in Appendix A7, we also explore an alternative indicator of embeddedness: the number of years an entrepreneur has been located in their neighborhood. Results using this measure of embeddedness show that the longer an entrepreneur has been located in their neighborhood the less valuable meeting a neighbor is. According to these results, meeting more proximate peers stops having a positive performance effect when entrepreneurs have been in their neighborhood for about 17 years or more. In our sample, only about $15 \%$ of entrepreneurs had been in their neighborhood for that amount of time or more.

Taken together, these results about entrepreneurs who participate in local associations and entrepreneurs who have been located in their neighborhood for an extended period of time strongly suggest that the performance effects we observe are contingent on entrepreneurs being under networked. In other words, for the small proportion of entrepreneurs that participate in local associations or has been located in their neighborhood for a long time, meeting a neighbor is not particularly valuable. Hence, the value of neighbors depends on entrepreneurs being relatively under networked. In our sample, this is the case for the majority of entrepreneurs.

In this section, we have presented three tests that explore whether being under networked drives our performance results. All three tests suggest that this is the case. They point in the direction of entrepreneurs being under networked and of the value of neighbors being contingent on that fact. These additional results paint a picture of entrepreneurs who are not locally embedded, but who bond with the neighbors they meet and learn from them, leading to improved performance. 


\section{Discussion and conclusion}

Who entrepreneurs talk to and network with has important implications for their performance, especially in the context of developing economies. Although existing research on peer learning suggests that we would expect entrepreneurs to benefit more from meeting a peer located further away from them, we find that, at least in the context of Togo, talking to more proximate peers tends to be more valuable. Using data from a training program that randomized who entrepreneurs met, we causally estimate the impact of peers' proximity on performance and find that having three discussion partners be $1 \mathrm{~km}$ nearer increases profits by $10 \%$ on average over the following year. Further analyses reveal that this is likely because most entrepreneurs are under-networked. In other words, entrepreneurs tend not to know enough neighbors to render their managerial knowledge redundant and when they meet they stay in touch. Moreover, for those few entrepreneurs who are well networked in their local communities the effect of peer proximity flips and meeting more distant peers improves performance more than meeting neighbors.

Our study contributes to three literatures. First, we contribute to the literature on peer learning by extending it to the context of developing economies. Existing research suggests that more geographically distant peers are useful because they serve as bridging ties, providing access to novel information or knowledge (McEvily and Zaheer 1999, Wang 2015). Despite the considerable research in this area, much of it is set in highly developed and interconnected environments, such as Silicon Valley (Kerr and Kominers 2015, Saxenian 1994), New York (Arzaghi and Henderson 2008), or Boston (Whittington et al. 2009). In contrast to these contexts, many developing economies are characterized by weak institutional support for interactions and poor transportation infrastructure, making it likelier that entrepreneurs are under networked. In such environments we find that entrepreneurs tend to gain more from being matched with neighbors, rather than more distant peers. This suggests that the conventional wisdom about the value of distant ties is likely contingent on the institutional and developmental context in which entrepreneurs are embedded.

This study also contributes to the literature on entrepreneurship and geography by showing that there may be untapped value in local communities, especially in developing economies. A substantial literature demonstrates that the co-location of firms leads to positive spillovers in terms of sharing knowledge and expertise, which benefits entrepreneurs (Sorenson and Audia 2000). Much of this literature tends to assume that this local knowledge is "in the air" (Ellison et al. 2010) 
and that local entrepreneurs and firms are exposed to it by virtue of their proximity to others. Although proximity certainly increases the probability of interactions among local entrepreneurs, our study suggests that when entrepreneurs are under networked there might be additional value that can be claimed through networking and socializing. Hence, it may be the case that in less economically developed contexts geographic spillovers aren't simply a matter of co-location, they're also a matter of being a good neighbor.

Finally, this study has implications for research on entrepreneurial ecosystems in developing economies. This literature explores the factors that enable local communities to catalyze entrepreneurial activity (Delgado et al. 2010, Saxenian 1994), often through organizations such as incubators (Cohen et al. 2019, Yu 2020) or local anchor institutions, like universities (Stam and Van de Ven 2021, Tartari and Stern 2021). Our study adds to these factors by highlighting the importance of local networking spaces and events. These are occasions that bring local entrepreneurs together and facilitate introductions. Although these may be prevalent in more developed economies, in the form of meetup groups or local chambers of commerce, in developing countries they are often lacking. Our results suggest that creating processes to connect local entrepreneurs may be key to effective public policy aiming to promote entrepreneurship and growth.

In addition to these main contributions, the results from our study also highlight how, in developing economies, there may be less of a tradeoff between cohesion and range in the value of ties. Many classic network accounts portray cohesive networks as beneficial for encouraging cooperation, while less cohesive networks with more weak ties provide a wider range of information (Aral and Van Alstyne 2011, Reagans and McEvily 2003, Tortoriello et al. 2012). Yet, because entrepreneurs are under networked, talking to a neighbor is equivalent to a distant outsider. At the same time, neighbors are still like "insiders" in that it is easier to build and sustain relationships with them. Because entrepreneurs are so far from the "social frontier" in our setting they can simultaneously gain on both of these dimensions.

It is worth noting that this study has several important limitations. First, our study is based on a relatively limited sample of entrepreneurs from a single institutional environment. In particular, the study is set in Togo, where the institutional environment is characterized by a lack of legal recourse for entrepreneurs, poor transportation infrastructure, and few local organizations that promote entrepreneurship. Although these conditions are representative of many sub-Saharan 
African economies, they are not representative of more developed economies. Therefore our results may or may not generalize to those contexts. Future work should explore whether entrepreneurs tend to be under networked in more developed economies and whether that changes the impact of meeting neighbors in places like Silicon Valley.

In addition to this, our data are also limited in terms of the geographic distances between entrepreneurs. Entrepreneurs in our sample were all from Lomé, which means that the furthest distance between matched entrepreneurs was the span of the city. This distance is considerable in the Togolese context because transportation is difficult and expensive, making it very time consuming to reach the other side of the city. Nevertheless, there could be benefits from meeting entrepreneurs even further away, perhaps in a different region of Togo or a different country, which we are unable to capture. Although we expect that the benefits of meeting neighbors will still outweigh those of meeting more distant peers when entrepreneurs are under networked, there are limits in the extent to which we can test this with our data. Future studies will hopefully explore whether there might be a u-shaped relationship between peer distance and performance, whereby peers at some extreme distances become similarly valuable to neighbors.

Further, this study is only focused on the role of geographic distance in affecting the value of meeting a peer entrepreneur. There are likely other factors that may affect the value of a peer, such as ethnic or gender homophily. Although our empirical strategy controls for these characteristics of the dyad, our limited sample does not permit us to explore how they may impact entrepreneurial performance or interact with distance. Future studies should explore whether, in addition to meeting neighboring peers, entrepreneurs also benefit more from meeting co-ethnic or same gender entrepreneurs.

Who entrepreneurs meet and talk to shapes their performance. In light of this, large literatures in management and organizations have explored how entrepreneurs network (Bensaou et al. 2013, Kuwabara et al. 2020), who entrepreneurs network with (Abraham 2019, Howell and Nanda 2019), and whether networking is impactful (Chatterji et al. 2019, Ingram and Morris 2007). This study explores an important, but often overlooked, type of peer - neighbors - and the relative value of networking with them. Our study emphasizes that in contexts where entrepreneurs tend to be under networked, which is likely to be the case in many developing countries, the relatively simple act of getting to know a neighbor is particularly valuable. We hope our results will 
encourage scholars to continue exploring other ways in which networking and peers can improve entrepreneurial performance, particularly in developing economies. 


\section{References}

Abraham M (2019) Gender-role incongruity and audience-based gender bias: An examination of networking among entrepreneurs. Admin. Sci. Quart. 65(1): 1-30.

Acharya A, Blackwell M, Sen M (2016) Explaining causal findings without bias: Detecting and assessing direct effects. Amer. Polit. Sci. Rev. 110(3): 512-529.

Ahuja G (2000) Collaboration networks, structural holes, and innovation: A longitudinal study. Admin. Sci. Quart. 45(3): 425-455.

Alcácer J, Chung W (2014) Location strategies for agglomeration economies. Strateg. Manage. J. 35(12): 1749-1761.

Almeida P, Kogut B (1999) Localization of knowledge and the mobility of engineers in regional networks. Manage. Sci. 45(7): 905-917.

Anderson SJ, Chintagunta PK, Germann F, Vilcassim N (2020) The impact of volunteer marketers on product differentiation and firm growth: A field experiment with ugandan entrepreneurs. Chicago Booth Research Paper(20-14).

Angrist JD, Lang K (2004) Does school integration generate peer effects? Evidence from boston's metco program. Amer. Econ. Rev. 94(5): 1613-1634.

Aral S, Van Alstyne M (2011) The diversity-bandwidth trade-off. Am. J. Sociol. 117(1): 90-171.

Armanios DE, Eesley CE, Li J, Eisenhardt KM (2017) How entrepreneurs leverage institutional intermediaries in emerging economies to acquire public resources. Strateg. Manage. J. 38(7): 1373-1390.

Arzaghi M, Henderson JV (2008) Networking off madison avenue. Rev. Econ. Stud. 75(4): 1011-1038.

Barthélemy M (2011) Spatial networks. Phys. Rep. 499(1-3): 1-101.

Bell GG, Zaheer A (2007) Geography, networks, and knowledge flow. Organ. Sci. 18(6): 955-972.

Bensaou BM, Galunic C, Jonczyk-Sédès C (2013) Players and purists: Networking strategies and agency of service professionals. Organ. Sci. 25(1): 29-56.

Cai J, Szeidl A (2018) Interfirm relationships and business performance. Quart. J. Econ. 133(3): 12291282.

Campos F, Frese M, Goldstein M, Iacovone L, Johnson HC, McKenzie D, Mensmann M (2017) Teaching personal initiative beats traditional training in boosting small business in west africa. Science 357(6357): 1287-1290.

Casciaro T, Gino F, Kouchaki M (2014) The contaminating effects of building instrumental ties: How networking can make us feel dirty. Admin. Sci. Quart. 59(4): 705-735.

Catalini C (2018) Microgeography and the direction of inventive activity. Manage. Sci. 64(9): 4348-4364.

Chan TY, Li J, Pierce L (2014) Learning from peers: Knowledge transfer and sales force productivity growth. Marketing Sci. 33(4): 463-484.

Chatterji A, Delecourt S, Hasan S, Koning RM (2019) When does advice impact startup performance? Strateg. Manage. J. 40(3): 331-356.

Chauvin J. 2019. When distance shrinks: The effects of competitor proximity on firm survival. Georgetown University, Washington, D.C.

Chung W, Alcácer J (2002) Knowledge seeking and location choice of foreign direct investment in the united states. Manage. Sci. 48(12): 1534-1554.

Cohen S, Fehder DC, Hochberg YV, Murray F (2019) The design of startup accelerators. Res. Pol. 48(7): 1781-1797.

Conley JF (2011) Estimation of exposure to toxic releases using spatial interaction modeling. International Journal of Health Geographics 10(1): 20-25.

Dahlander L, McFarland DA (2013) Ties that last: Tie formation and persistence in research collaborations over time. Admin. Sci. Quart. 58(1): 69-110.

De Mel S, McKenzie DJ, Woodruff C (2009) Measuring microenterprise profits: Must we ask how the sausage is made? J. Devel. Econ. 88(1): 19-31. 
De Vries JJ, Nijkamp P, Rietveld P (2009) Exponential or power distance-decay for commuting? An alternative specification. Env. Plan. 41(2): 461-480.

Declare Design. 2018. The trouble with 'controlling for blocks'. Blog.

Delgado M, Porter ME, Stern S (2010) Clusters and entrepreneurship. J. Econ. Geogr. 10(4): 495-518.

Dimitriadis S (2021) Social capital and entrepreneur resilience: Entrepreneur performance during violent protests in togo. Strateg. Manage. J. 42(11): 1993-2019.

Eesley C, Wang Y (2017) Social influence in career choice: Evidence from a randomized field experiment on entrepreneurial mentorship. Res. Pol. 46(3): 636-650.

Ellison G, Glaeser EL, Kerr WR (2010) What causes industry agglomeration? Evidence from coagglomeration patterns. Amer. Econ. Rev. 100(3): 1195-1213.

Fafchamps M (2006) Development and social capital. J. Devel. Stud. 42(7): 1180-1198.

Fafchamps M, McKenzie D, Quinn S, Woodruff C (2012) Using pda consistency checks to increase the precision of profits and sales measurement in panels. J. Devel. Econ. 98(1): 51-57.

Fafchamps M, Quinn S (2018) Networks and manufacturing firms in africa: Results from a randomized field experiment. World Bank Econ. Rev. 32(3): 656-675.

Fotheringham AS (1981) Spatial structure and distance-decay parameters. Ann. Ass. Americ. Geogr. 71(3): 425-436.

Gibbons CE, Serrato JCS, Urbancic MB (2019) Broken or fixed effects? J. Econometric Meth. 8(1).

Granovetter MS (1973) The strength of weak ties. Am. J. Sociol. 78(6): 1360-1380.

Hallen BL, Eisenhardt KM (2012) Catalyzing strategies and efficient tie formation: How entrepreneurial firms obtain investment ties. Acad. Manage. J. 55(1): 35-70.

Hargadon A, Sutton RI (1997) Technology brokering and innovation in a product development firm. Admin. Sci. Quart. 716-749.

Hasan S, Bagde S (2013) The mechanics of social capital and academic performance in an indian college. Am. Sociol. Rev. 78(6): 1009-1032.

Hasan S, Koning R (2019) Conversations and idea generation: Evidence from a field experiment. Res. Pol. 48(9): 103811.

Hasan S, Koning R (2019) Prior ties and the limits of peer effects on startup team performance. Strateg. Manage. J. 40(9): 1394-1416.

Hjort J (2014) Ethnic divisions and production in firms. Quart. J. Econ. 129(4): 1899-1946.

Howell ST, Nanda R. 2019. Networking frictions in venture capital, and the gender gap in entrepreneurship. National Bureau of Economic Research.

Ingram P, Morris MW (2007) Do people mix at mixers? Structure, homophily, and the "life of the party". Admin. Sci. Quart. 52(4): 558-585.

Ingram P, Roberts PW (2000) Friendships among competitors in the sydney hotel industry. Am. J. Sociol. 106(2): 387-423.

Kalnins A, Chung W (2004) Resource-seeking agglomeration: A study of market entry in the lodging industry. Strateg. Manage. J. 25(7): 689-699.

Kerr WR, Kominers SD (2015) Agglomerative forces and cluster shapes. Rev. Econ. Statist. 97(4): 877899.

Khanna T (2018) Trust: Creating the foundation for entrepreneurship in developing countries (BerrettKoehler Publishers, Oakland, CA).

Khanna T, Palepu KG (2010) Winning in emerging markets: A road map for strategy and execution (Harvard Business School Press, Cambridge: MA).

Kleinbaum AM, Stuart TE, Tushman ML (2013) Discretion within constraint: Homophily and structure in a formal organization. Organ. Sci. 24(5): 1316-1336.

Kling JR, Liebman JB, Katz LF (2007) Experimental analysis of neighborhood effects. Econometrica 75(1): 83-119.

Klüppel LM, Pierce L, Snyder JA (2018) The deep historical roots of organization and strategy: Traumatic shocks, culture, and institutions. Organ. Sci. 29(4): 702-721. 
Kuwabara K, Hildebrand CA, Zou X (2018) Lay theories of networking: How laypeople's beliefs about networks affect their attitudes toward and engagement in instrumental networking. Acad. Manage. Rev. 43(1): 50-64.

Kuwabara K, Zou X, Aven B, Hildebrand C, Iyengar S (2020) Lay theories of networking ability: Beliefs that inhibit instrumental networking. Social Networks 62 1-11.

Lerner J, Malmendier U (2013) With a little help from my (random) friends: Success and failure in postbusiness school entrepreneurship. Rev. Finan. Stud. 26(10): 2411-2452.

Manski CF (1993) Identification of endogenous social effects: The reflection problem. Rev. Econ. Stud. 60(3): 531-542.

McEvily B, Zaheer A (1999) Bridging ties: A source of firm heterogeneity in competitive capabilities. Strateg. Manage. J. 20(12): 1133-1156.

McKenzie D (2021) Small business training to improve management practices in developing countries: Re-assessing the evidence for 'training doesn't work'. Oxford Rev. Econ. Pol. 37(2): 276-301.

McKenzie D, Woodruff C (2014) What are we learning from business training and entrepreneurship evaluations around the developing world? World Bank Res. Observ. 29(1): 48-82.

McKenzie D, Woodruff C (2018) Business practices in small firms in developing countries. Manage. Sci. 63(9): 2967-2981.

Montgomery JM, Nyhan B, Torres M (2018) How conditioning on posttreatment variables can ruin your experiment and what to do about it. Am. J. Pol. Sci. 62(3): 760-775.

Nanda R, Khanna T (2010) Diasporas and domestic entrepreneurs: Evidence from the indian software industry. J. Econ. Manag. 19(4): 991-1012.

Pun-Cheng LS. 2016. Distance decay. John Wiley \& Sons, Hoboken, NJ.

Putnam RD (2000) Bowling alone: America's declining social capital (Simon and Schuster, New York, NY).

Reagans R, McEvily B (2003) Network structure and knowledge transfer: The effects of cohesion and range. Admin. Sci. Quart. 48(2): 240-267.

Rosenkopf L, Almeida P (2003) Overcoming local search through alliances and mobility. Manage. Sci. 49(6): 751-766.

Rosenthal SS, Strange WC (2001) The determinants of agglomeration. J. Urban Econ. 50(2): 191-229.

Ruef M, Kwon S-W (2016) Neighborhood associations and social capital. Soc. Forces 95(1): 159-190.

Saxenian A (1994) Regional advantage: Culture and competition in silicon valley and route 128 (Harvard University Press, Cambridge, MA).

Shane S, Cable D (2002) Network ties, reputation, and the financing of new ventures. Manage. Sci. 48(3): 364-381.

Small ML, Adler L (2019) The role of space in the formation of social ties. Annu. Rev. Sociol. 45111 132.

Sorenson O, Audia PG (2000) The social structure of entrepreneurial activity: Geographic concentration of footwear production in the united states, 1940-1989. Am. J. Sociol. 106(2): 424-462.

Stam E, Van de Ven A (2021) Entrepreneurial ecosystem elements. Small Bus. Econ. 56(2): 809-832.

Tartari V, Stern S. 2021. More than an ivory tower: The impact of research institutions on the quantity and quality of entrepreneurship. National Bureau of Economic Research.

Tortoriello M, Reagans R, McEvily B (2012) Bridging the knowledge gap: The influence of strong ties, network cohesion, and network range on the transfer of knowledge between organizational units. Organ. Sci. 23(4): 1024-1039.

United Nations Development Programme (2017) Human development indicators: Togo (Human Development Reports, New York, NY).

US Embassy in Togo. 2019. Creating a new ecosystem of social entrepreneurs (11 june, 2019). US State Department, https://tg.usembassy.gov/creating-a-new-ecosystem-of-social-entrepreneurs/.

Uzzi B, Dunlap S (2005) How to build your network. Harvard Bus. Rev. 83(12): 53.

Vega-Redondo F, Pin P, Ubfal D, Benedetti-Fasil C, Brummitt C, Rubera G, Hovy D, Fornaciari T (2019) Peer networks and entrepreneurship: A pan-african rct. 
Vissa B, Chacar AS (2006) External networks of entrepreneurial teams and high technology venture performance in emerging markets. Entrepreneurial Strategies: New Technologies in Emerging Markets 187-205.

Vissa B, Chacar AS (2009) Leveraging ties: The contingent value of entrepreneurial teams' external advice networks on indian software venture performance. Strateg. Manage. J. 30(11): 1179-1191.

Wang D (2015) Activating cross-border brokerage: Interorganizational knowledge transfer through skilled return migration. Admin. Sci. Quart. 60(1): 133-176.

Whittington KB, Owen-Smith J, Powell WW (2009) Networks, propinquity, and innovation in knowledge-intensive industries. Admin. Sci. Quart. 54(1): 90-122.

World Bank. 2016. Country highlights togo. World Bank Group, Washington, D.C.

Yenkey CB (2015) Mobilizing a market: Ethnic segmentation and investor recruitment into the nairobi securities exchange. Admin. Sci. Quart. 60(4): 561-595.

Yu S (2020) How do accelerators impact the performance of high-technology ventures? Manage. Sci. 66(2): 530-552.

Zuckerman EW, Sgourev SV (2006) Peer capitalism: Parallel relationships in the us economy. Am. J. Sociol. 111(5): 1327-1366. 
Figure 1: Spatial Distribution of Proximity to Peers

Panel A: Distance of closest randomized peer

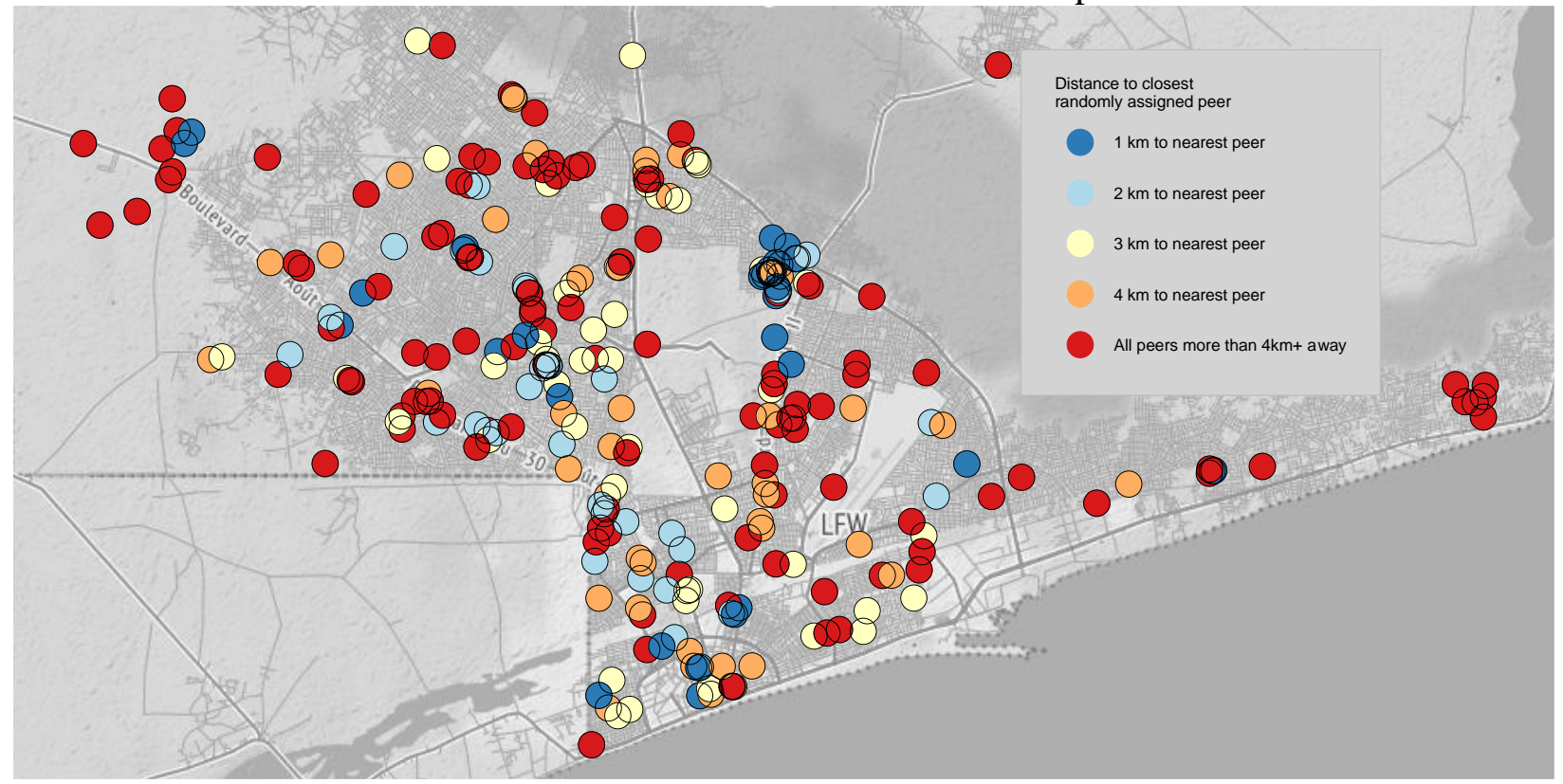

Panel B: Average proximity (as defined in Equation 2) of randomly assigned peers

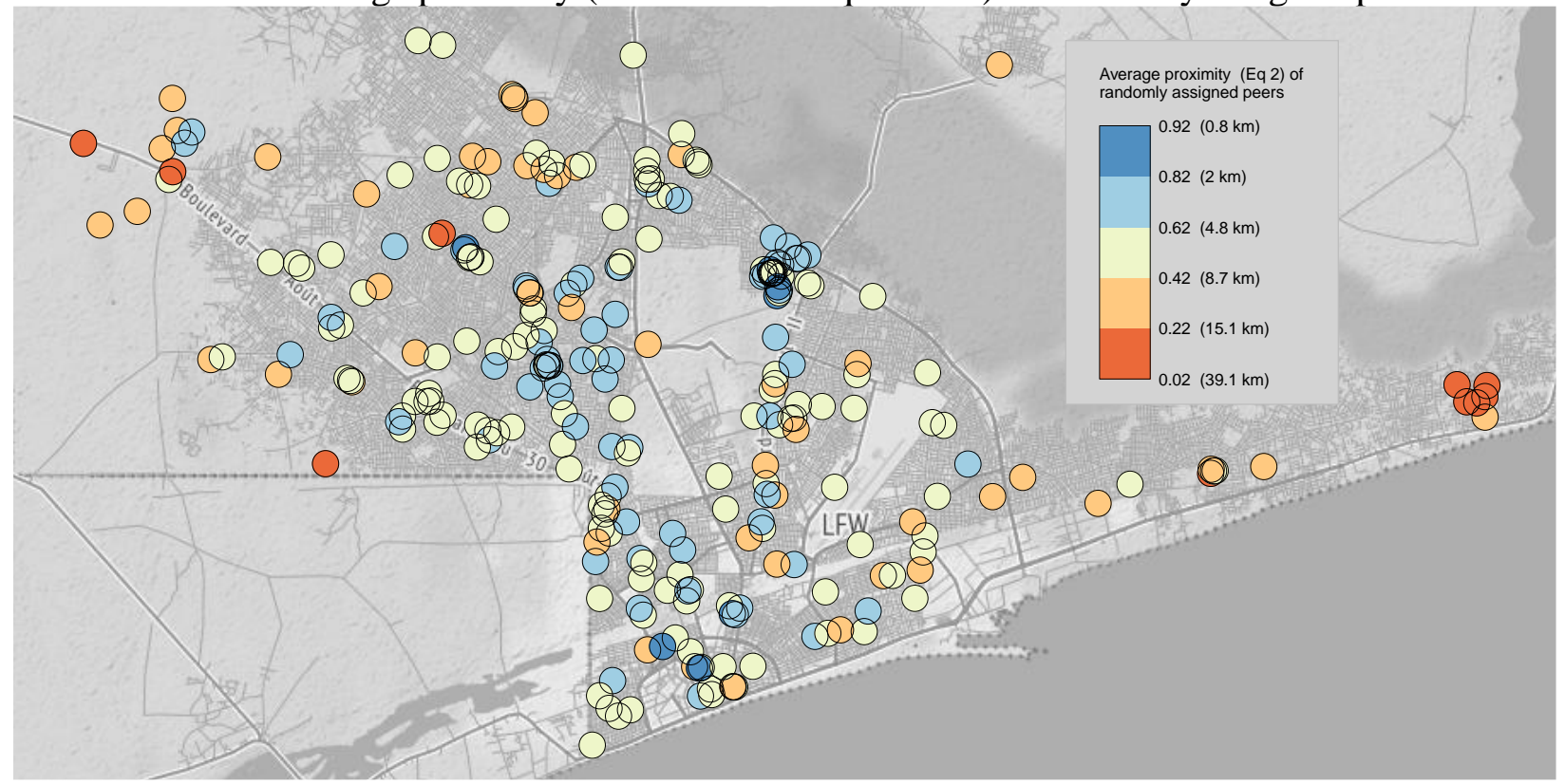

Note: These maps show the approximate location of entrepreneurs' businesses in the city of Lomé. Entrepreneurs' locations are color coded to reflect the extent to which they were treated, i.e. the distance to the closest peer (Panel A) or the average proximity (Panel B) of their randomly assigned discussion peers. Shades of blue show entrepreneurs exposed to neighbors, while shades of red show entrepreneurs introduced to distant peers. These figures show the treatment is not simply reducible to differences in neighborhood density, rather there is variation both across, and most importantly within, neighborhoods. 
Figure 2: Proximate discussion peers increase performance

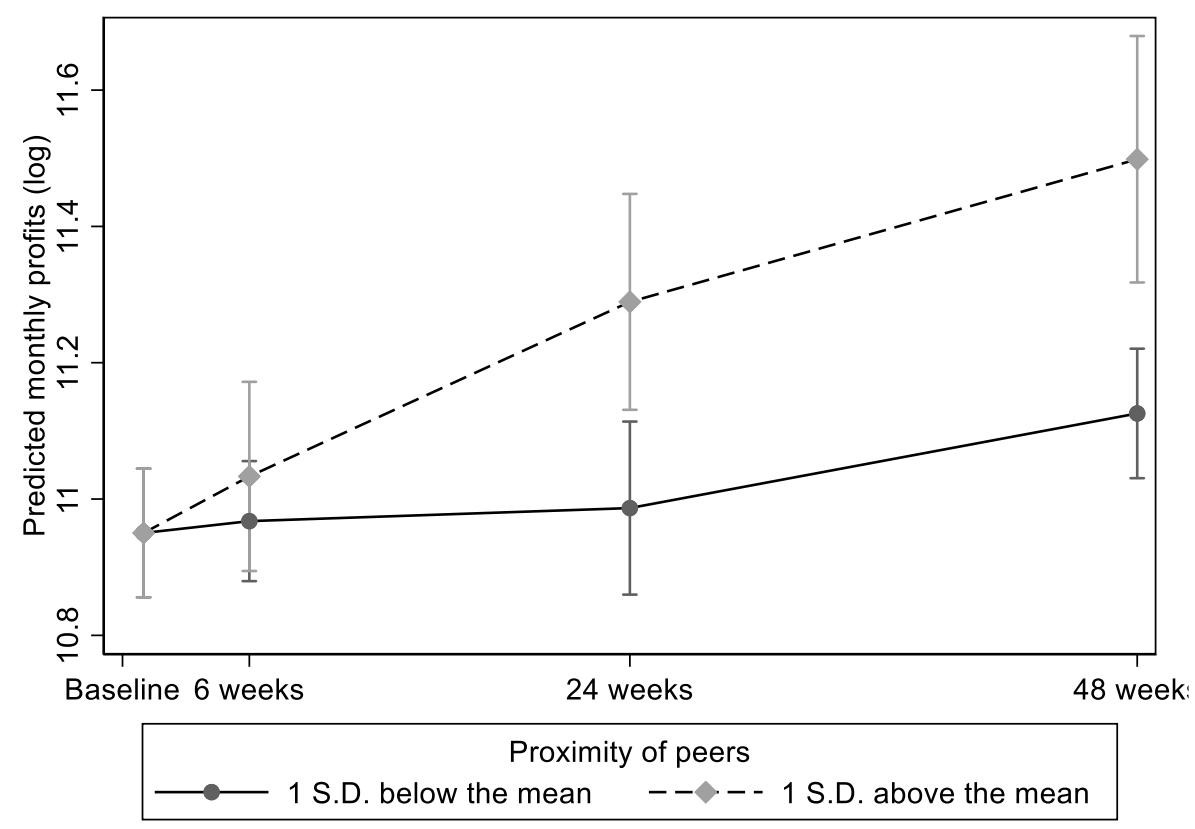

Note: The plot above compares the predicted log monthly profits for entrepreneurs who were randomly assigned discussion peers one standard deviation below and above the mean in terms of their proximity. Bars represent 95\%confidence intervals. Profits for entrepreneurs with peers one standard deviation above the mean (grey dashed line) indicate an increasing pattern, while those assigned peers one standard deviation below the mean do not significant increases in performance. 
Figure 3: Coefficient plot of discussion peers' performance effect by expanding radii

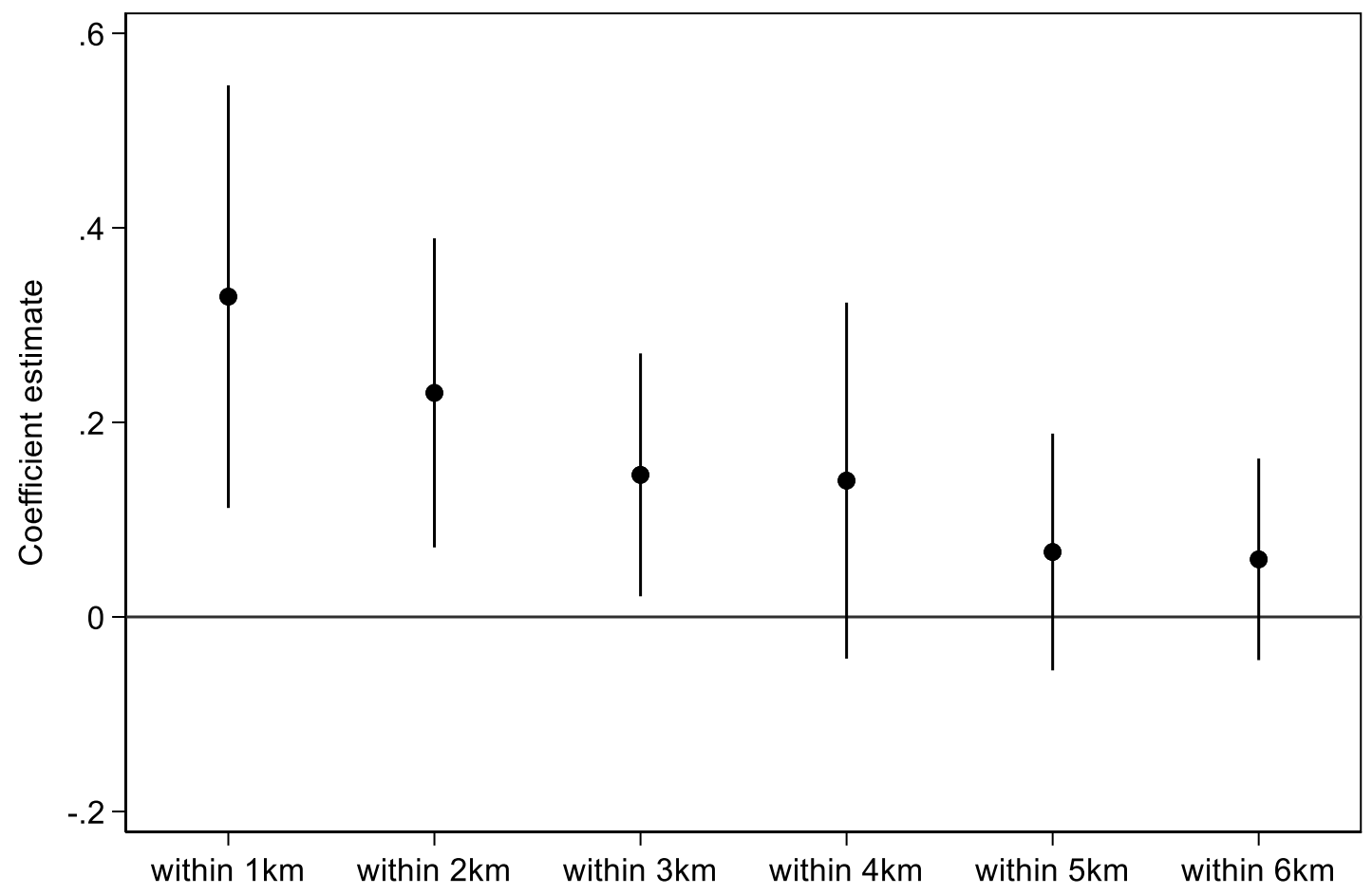

Note: The points plotted in the figure above represent coefficient estimates from regressions of monthly profits on the number of discussion peers within different radii of the focal entrepreneur, shown in Table 3. The vertical bars represent standard errors, which were clustered at the neighborhood level in the regressions. As expected, the effect of peers on performance decreases with distance, becoming statistically non-significant at approximately $4 \mathrm{~km}$. 
Figure 5: Proximity increases the probability of tie formation

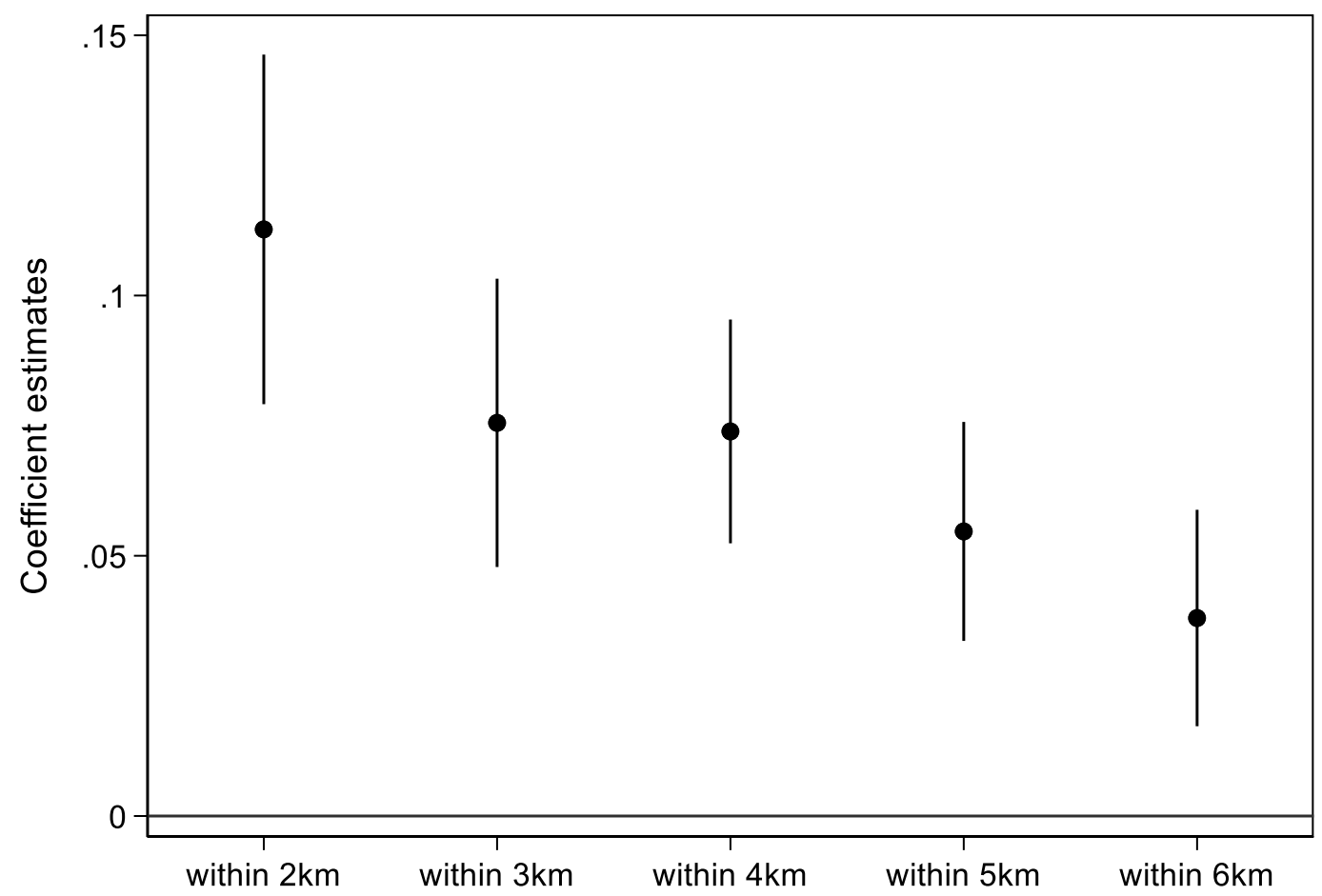

Note: This figure plots the coefficient estimates from Table 5, which indicate the effect of proximity on the formation of a tie between the entrepreneur and their assigned peer. Proximity is measured at different radii around the entrepreneur. The figure shows that as the radius around the entrepreneur increases, the likelihood they will remain in touch with their assigned peer decreases. 
Figure 6: The effect of peer proximity on management practices

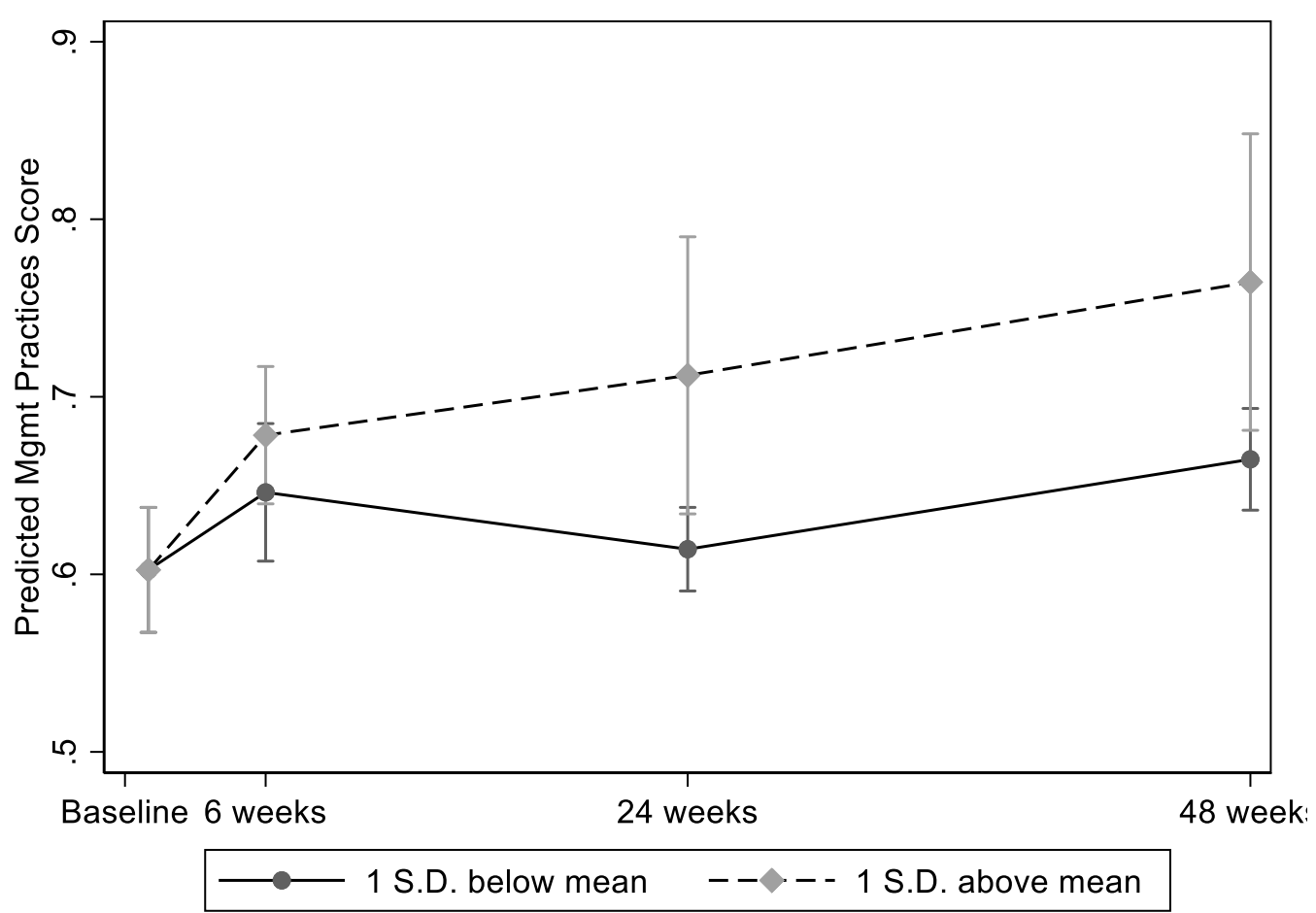

Note: This figure plots the average predicted management score for entrepreneurs who were 1 standard deviation above and below the mean in terms of the proximity of their assigned peers. The predicted values are based on the coefficient estimates from Table 4. The pattern illustrated by the figure is that entrepreneurs with peers who are nearby continue to learn over time, after their initial meeting at baseline. 
Figure 7: Local association membership inverts the effect of proximity on performance

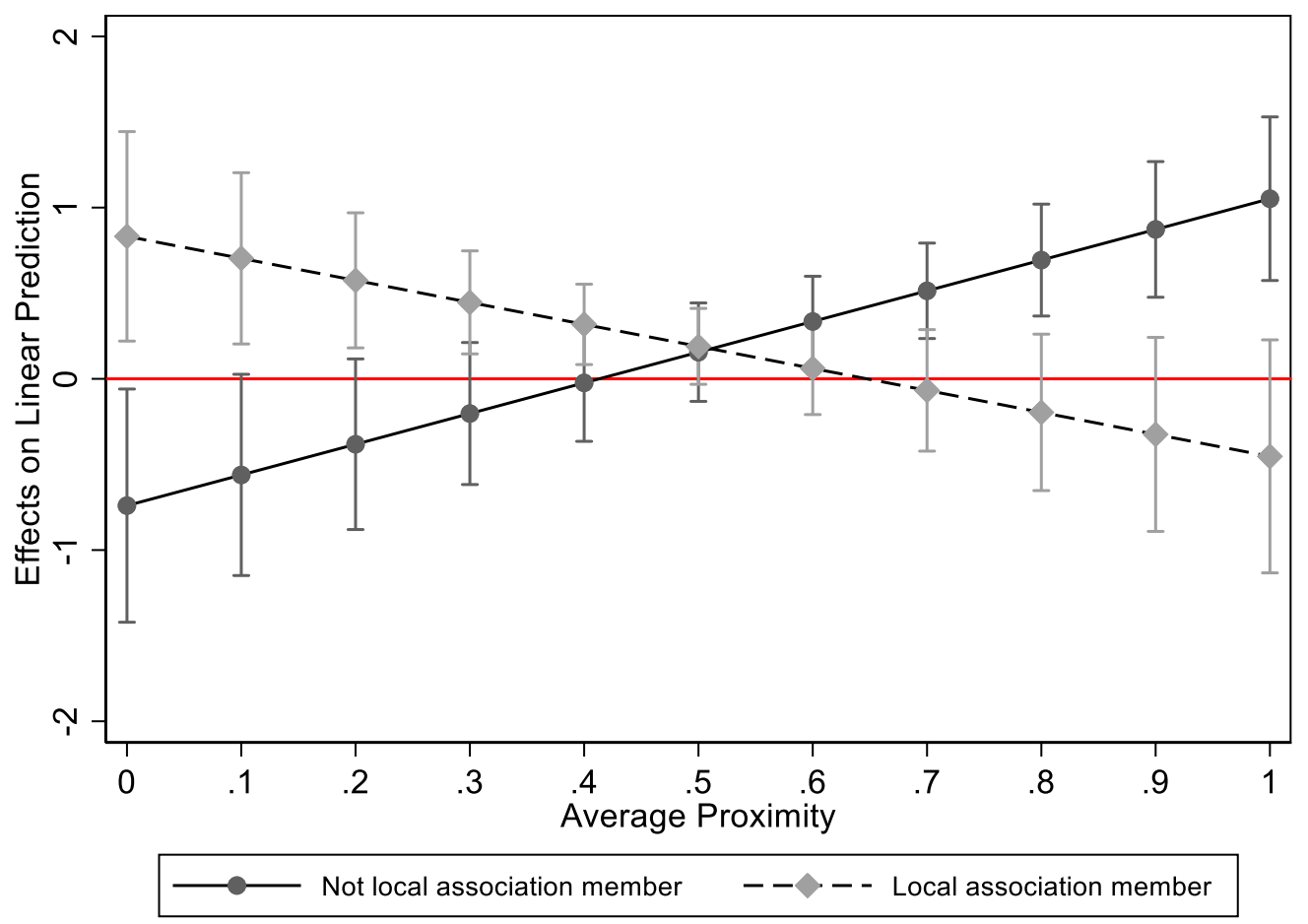

Note: This figure plots the average predicted effect of proximity on log monthly profits when entrepreneurs are members of a local association compared to when they aren't. For entrepreneurs who participate in local associations, as the proximity of assigned peers increases their performance increases, while the inverse is true for entrepreneurs who do participate in a local association. 
Table 1: Baseline summary statistics

\begin{tabular}{lccccccc}
\hline & Mean & S.D. & Min & $25^{\text {th }}$ pctl & Median & $75^{\text {th }}$ pctl & $\max$ \\
\hline Profits (log) & 10.942 & 1.146 & 8.294 & 10.127 & 10.820 & 11.608 & 14.670 \\
Performance index & -0.058 & 0.805 & -1.595 & -0.622 & -0.175 & 0.276 & 4.806 \\
Ave. proximity & 0.534 & 0.155 & 0.017 & 0.440 & 0.536 & 0.644 & 0.917 \\
Peers within 1km & 0.142 & 0.390 & 0 & 0 & 0 & 0 & 2 \\
Peers within 2km & 0.270 & 0.499 & 0 & 0 & 0 & 0 & 2 \\
Peers within 3km & 0.500 & 0.653 & 0 & 0 & 0 & 1 & 2 \\
Peers within 4km & 0.745 & 0.751 & 0 & 0 & 1 & 1 & 3 \\
Peers known from before & 0.478 & 0.844 & 0 & 0 & 0 & 1 & 3 \\
Social skills & 0.504 & 0.501 & 0 & 0 & 1 & 1 & 1 \\
Management practices score & 0.593 & 0.257 & 0 & 0.407 & 0.630 & 0.778 & 1 \\
Local association member & 0.113 & 0.317 & 0 & 0 & 0 & 0 & 1 \\
\hline
\end{tabular}

$\mathrm{N}=274$ 
Table 2: The impact of average peer proximity on performance

\begin{tabular}{|c|c|c|c|c|c|c|}
\hline & \multicolumn{5}{|c|}{ Monthly Profits (log) } & \multirow{2}{*}{$\begin{array}{c}\begin{array}{c}\text { Performance } \\
\text { Index }\end{array} \\
(6)\end{array}$} \\
\hline & (1) & (2) & (3) & (4) & (5) & \\
\hline Post-Training X Ave. proximity & $\begin{array}{l}1.247^{*} \\
(0.516)\end{array}$ & & & & & $\begin{array}{l}1.162^{*} \\
(0.464)\end{array}$ \\
\hline Post-Training X Peers within $1 \mathrm{~km}$ & & $\begin{array}{c}0.329 * * \\
(0.108)\end{array}$ & & & & \\
\hline Post-Training X Peers within $2 \mathrm{~km}$ & & & $\begin{array}{c}0.230 * * \\
(0.079)\end{array}$ & & & \\
\hline Post-Training X Peers within $3 \mathrm{~km}$ & & & & $\begin{array}{l}0.146^{*} \\
(0.062)\end{array}$ & & \\
\hline Post-Training X Peers within 4km & & & & & $\begin{array}{c}0.140 \\
(0.091)\end{array}$ & \\
\hline Entrepreneur FE & Yes & Yes & Yes & Yes & Yes & Yes \\
\hline Survey wave FE & Yes & Yes & Yes & Yes & Yes & Yes \\
\hline$N$ & 1033 & 1033 & 1033 & 1033 & 1033 & 1033 \\
\hline Entrepreneurs & 274 & 274 & 274 & 274 & 274 & 274 \\
\hline
\end{tabular}

Note: All models include interactions between the number of peers entrepreneurs knew from before the program and their social skills with the post-training indicator, as well as the indicator for post-training time periods. Inverse propensity score weights included in all models. Robust standard errors clustered by entrepreneurs' neighborhood in parentheses. $+p<0.10, * p<0.05, * * p<0.01$ 
Table 3: The effect of proximity on tie formation

(1) (2) (3)

(4)

(5)

Ave. proximity $\quad 0.194 * *$

(0.029)

Peer within $1 \mathrm{~km}$

$0.196 * *$

(0.026)

Peer within $2 \mathrm{~km}$

$0.108 * *$

$(0.017)$

Peer within $3 \mathrm{~km}$

$0.070 * *$

Peer within $4 \mathrm{~km}$

(0.014)

$0.071 * *$

(0.010)

$\begin{array}{lccccc}\text { Survey wave FE } & \text { Yes } & \text { Yes } & \text { Yes } & \text { Yes } & \text { Yes } \\ \text { Entrepreneur FE } & \text { Yes } & \text { Yes } & \text { Yes } & \text { Yes } & \text { Yes } \\ \text { Peer Entrepreneur FE } & \text { Yes } & \text { Yes } & \text { Yes } & \text { Yes } & \text { Yes }\end{array}$

\begin{tabular}{lccccc}
\hline$N$ & 14,670 & 14,670 & 14,670 & 14,670 & 14,670 \\
Entrepreneurs & 274 & 274 & 274 & 274 & 274 \\
Dyads & 4,109 & 4,109 & 4,109 & 4,109 & 4,109 \\
\hline
\end{tabular}

Note: All models control for entrepreneur social skills and whether the peer was known from before. The models are based on data from the three time periods after the networking event. Robust standard errors multiway clustered by ego, alter, and dyad in parentheses. 
Table 4: The impact of average peer proximity on management practices score Management Practices Score

(1) (2) (3) (4)

Post-Training X Ave. proximity $0.390 * *$

$(0.115)$

Post-Training X Peers within $1 \mathrm{~km}$

$0.126^{* *}$

$(0.032)$

Post-Training X Peers within $2 \mathrm{~km}$

$0.079^{*}$

Post-Training X Peers within 3km

$(0.035)$

Post-Training X Peers within 4km

$0.045+$

$(0.024)$

\begin{tabular}{lccccc}
$\begin{array}{l}\text { Entrepreneur FE } \\
\text { Survey wave FE }\end{array}$ & $\begin{array}{c}\text { Yes } \\
\text { Yes }\end{array}$ & $\begin{array}{c}\text { Yes } \\
\text { Yes }\end{array}$ & $\begin{array}{c}\text { Yes } \\
\text { Yes }\end{array}$ & $\begin{array}{c}\text { Yes } \\
\text { Yes }\end{array}$ & $\begin{array}{c}\text { Yes } \\
\text { Yes }\end{array}$ \\
\hline$N$ & 1033 & 1033 & 1033 & 1033 & 1033 \\
Entrepreneurs & 274 & 274 & 274 & 274 & 274 \\
\hline
\end{tabular}

Note: All models include interactions between the number of peers entrepreneurs knew from before the program and their social skills with the post-training indicator, as well as an indicator for post-training time periods. IPW weights included in both models. Robust standard errors clustered by entrepreneurs' neighborhood in parentheses. $+p<0.10, * p<$ $0.05, * * p<0.01$ 
Table 5: The impact of average peer proximity on performance

\begin{tabular}{ccc}
$\begin{array}{c}\text { Monthly profits } \\
(\log )\end{array}$ & $\begin{array}{c}\text { Performance } \\
\text { Index }\end{array}$ \\
\cline { 1 - 1 } & $(2)$
\end{tabular}

Post-training X Ave. Proximity X Local association member

$-2.776^{* *}$

(0.753)

$0.856^{*}$

$(0.364)$

$1.546 * *$

(0.564)

Yes

Yes
$-1.559 *$

$(0.621)$

$0.753+$

$(0.375)$

$1.364^{*}$

(0.516)

Yes

Yes

Survey wave FE

1033

1033

Entrepreneurs

274

274

Note: All models include interactions between the number of peers entrepreneurs knew from before the program and their social skills with the post-training indicator, as well as an indicator for post-training time periods. IPW weights included in both models. Robust standard errors clustered by entrepreneurs' neighborhood in parentheses. $+p<0.10, * p<0.05, * * p<0.01$ 


\section{APPENDIX \\ Won't you be my neighbor? \\ Geography, peer learning, and entrepreneur performance in Togo}

January 30,2022

1. Empirical setting and descriptive data

2. Randomization and sample balance

3. Results without inverse propensity weights

4. Results dropping entrepreneurs without proximate peers

5. Modeling proximity with alternative decay functions

6. Temporal Dynamics

7. Additional measures of neighborhood embeddedness

8. Knowing peers before the training program

9. Similarity between entrepreneurs and peers in managerial knowledge

10. Dyad Performance Regressions

11. Performance results with different control variable configurations

12. Are proximate peers likelier to become clients, suppliers, or provide referrals

13. Minimum detectable effect size and power calculations 


\section{A1 Empirical setting and data}

\section{Lomé, Togo}

This study is set in the city of Lomé, which is the capital of the West African country Togo. In 2016, the approximate population of Lomé was 2 million people, which is a little over a quarter of the country's population (World Bank 2016). The city's infrastructure is relatively underdeveloped and most economic activity is concentrated in services, trade, and processing of agricultural goods (World Bank 2019).

\section{The training program}

The data for the present study come from a training program for entrepreneurs that took place in April-May 2017. The program trained entrepreneurs in basic marketing practices and was based on the ILO's "Improve your business" curriculum and took place over the course of two workdays. The program was run by a local nonprofit organization "Association des jeunes entrepreneurs du Togo" and was taught by two local management consultants, who had previously taught the materials in other training programs and at local universities. After a month of advertising and canvassing to solicit participants, the program accepted 303 entrepreneurs, each of whom had been in operation for at least 1 year.

This training program was also used as a setting for the field experiment to study "social skills" training, which was randomized at the level of classroom cohorts. This social skills training was given at the start of the two day training. The authors then measured entrepreneurs' interactions with other participants and surveyed them three times after the end of the training. They found that entrepreneurs who received social skills training formed more new ties with co-participants, those ties were more skill complementary, and their profits increased in the year after the program.

A feature of the training program was the "structured" networking event at the end of the second day. This structured networking event consisted of randomly pairing entrepreneurs with 3 other participants for one-on-one discussions that each lasted approximately 30-45 minutes. This networking event was originally used to measure differences in communication among entrepreneurs who received the social skills training and those who did not.

In the present study, rather than examining differences in communication, we are interested in the effect of entrepreneurs' discussions during the networking event in and of themselves and the impact they may have had on entrepreneurs' performance. Since entrepreneurs were randomly assigned to their discussion peers and this randomization was independent from the randomization into social skills training, we have exogenous variation in the extent to which entrepreneurs met and talked to peers who were near or further away from them. Since the focus of this study is on the effect of peer proximity on entrepreneur performance, the main independent variable of interest (peer proximity) was not part of the original study by Dimitriadis and Koning (forthcoming).

\section{The data}

Data come from two sources: a longitudinal survey of participant entrepreneurs and the entrepreneurs' pairings during the networking event. The longitudinal survey provides information about performance, social networks, location, management practices, and formation of ties with co-participants from before the training program to 1 year after. Using these surveys, we created 
two datasets: an entrepreneur-level dataset and an entrepreneur dyad-level dataset. The entrepreneur-level dataset averages information about entrepreneurs' randomly assigned discussion peers and hence the unit of observation is the entrepreneur at each given time period. The dyad-level dataset is at the level of discussion partners, and thus each observation is at the level of a matched pair of entrepreneurs.

Table A1.2 shows the pairwise correlations for the variables from the entrepreneur-level data used in our analyses at baseline. The correlations suggest that the variables are related to each other in ways that we might expect. Higher performing firms tend to have more employees and a higher management practices score. Older firms tend to have better management practices, even though their owners often do not have more formal education.

Figure A1.1 plots the kernel density function for monthly profits (log) at baseline. This plot is helpful in showing that the distribution of profits is Gaussian (Normal), with potentially a smaller number of high performing entrepreneurs.

Table A1.1: Correlation matrix

$\begin{array}{lllllllllll}1 & 2 & 3 & 4 & 5 & 6 & 7 & 8 & 9 & 10 & 11\end{array}$

\begin{tabular}{lllllllllllll}
\hline 1 & Profits (log) & & & & & & & & & & \\
2 & Performance index & 0.833 & & & & & & & & & \\
3 & Ave. proximity & -0.117 & -0.085 & & & & & & & & \\
4 & Peers known from before & -0.121 & -0.109 & 0.019 & & & & & & & \\
5 & Social skills & -0.081 & -0.103 & -0.084 & 0.024 & & & & & & \\
6 & Ewe ethnicity & 0.022 & 0.039 & -0.132 & 0.027 & 0.053 & & & & & \\
7 & Female & -0.108 & -0.032 & -0.009 & 0.107 & 0.105 & -0.135 & & & & \\
8 & Primary School Completed & 0.014 & 0.002 & 0.086 & -0.076 & -0.138 & -0.083 & 0.000 & & & \\
9 & Employees & 0.294 & 0.376 & 0.020 & -0.083 & -0.069 & -0.047 & -0.067 & 0.009 & & \\
10 & Firm age & 0.066 & 0.079 & -0.095 & 0.094 & 0.240 & 0.182 & 0.064 & -0.418 & -0.001 & \\
11 & Mgmt practices score & 0.277 & 0.265 & -0.111 & -0.021 & 0.041 & 0.044 & 0.052 & -0.108 & 0.139 & 0.241 \\
12 & Class size & -0.121 & -0.120 & -0.145 & 0.140 & 0.398 & 0.111 & 0.101 & -0.038 & -0.063 & 0.087 & -0.066 \\
\hline & N = 274 & & & & & & & & & & &
\end{tabular}


Figure A1.1: Monthly profits (log) distribution at baseline

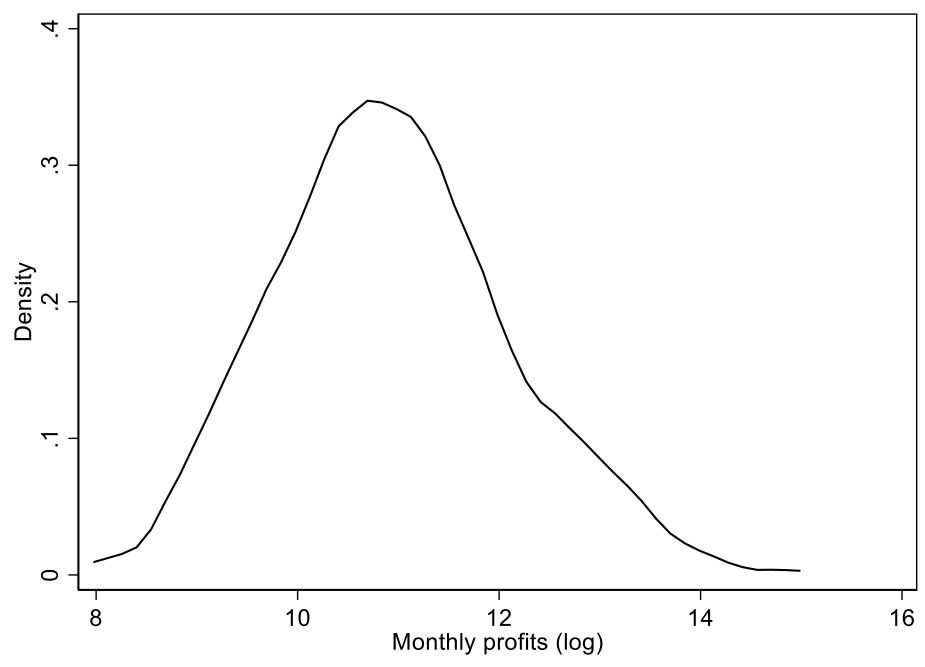

Figure A1.2 shows the kernel density function for average peer proximity, which is our main independent variable of interest. This variable averages the proximity of each entrepreneurs' three discussion peers. The variable ranges from 0 to 1 , with 0 meaning infinitely distant and 1 meaning at a distance of 0 meters from each other. As the figure shows, the average proximity for the three assigned peers follows an approximately Gaussian distribution.

Figure A1.2: Distribution of average peer proximity

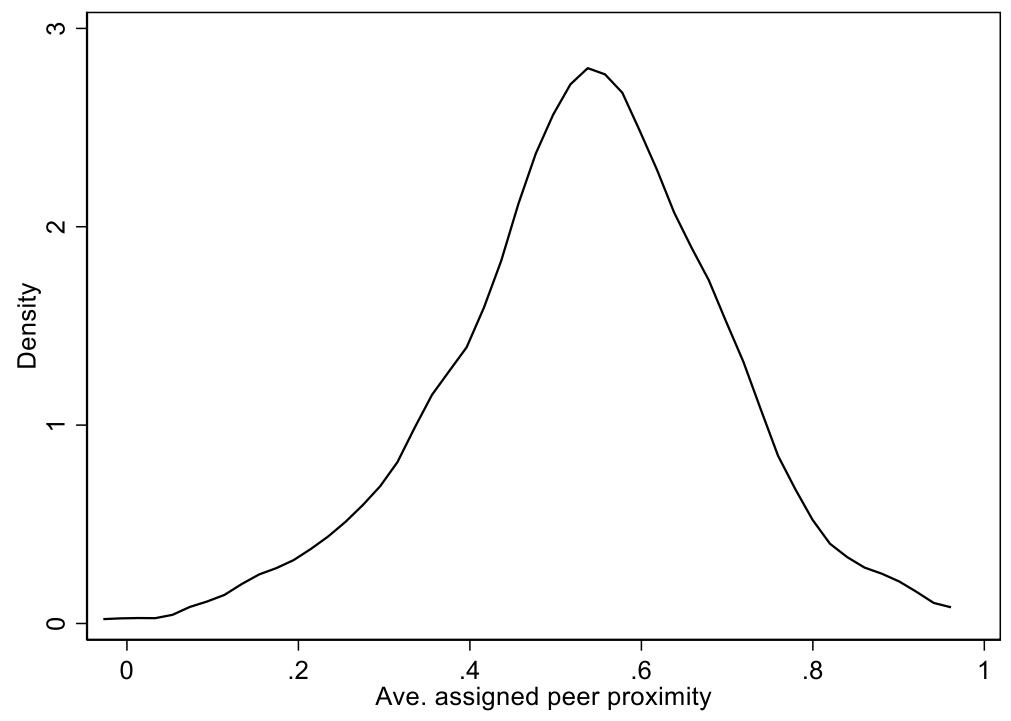

Tables A1.2 and A1.3 provide descriptive statistics for the dyad-level data. In this dataset each observation is at the level of a matched discussion pair of entrepreneurs. These tables provide descriptive statistics for the variables used in the analyses for the dyadic performance effects, the probability of forming a tie, and the similarity in managerial knowledge between entrepreneurs. 
Table A1.2: Dyadic data summary statistics

\begin{tabular}{lcrrrrrr}
\hline & & & & 25 th & & $75^{\text {th }}$ \\
& Mean & S.D. & Min & pctl & Median & pctl & Max \\
\hline Tie formed & 0.140 & 0.347 & 0 & 0 & 0 & 0 & 1 \\
Proximity & 0.532 & 0.214 & 0.013 & 0.380 & 0.536 & 0.694 & 0.998 \\
Peer within 1km & 0.053 & 0.224 & 0 & 0 & 0 & 0 & 1 \\
Peer within 2km & 0.096 & 0.294 & 0 & 0 & 0 & 0 & 1 \\
Peer within 3km & 0.182 & 0.386 & 0 & 0 & 0 & 0 & 1 \\
Peer within 4km & 0.269 & 0.444 & 0 & 0 & 0 & 1 & 1 \\
Management Practices Difference & 7.359 & 4.699 & 0 & 4 & 7 & 10 & 25 \\
Marketing Practices Difference & 1.588 & 1.592 & 0 & 0 & 1 & 2 & 7 \\
Stock Practices Difference & 1.313 & 1.090 & 0 & 1 & 1 & 2 & 5 \\
Planning Practices Difference & 1.595 & 1.579 & 0 & 0 & 1 & 3 & 6 \\
Financial Practices Difference & 2.091 & 1.650 & 0 & 1 & 2 & 3 & 7 \\
Social skills training & 0.480 & 0.500 & 0 & 0 & 0 & 1 & 1 \\
Knew peer from before & 0.175 & 0.380 & 0 & 0 & 0 & 0 & 1 \\
\hline
\end{tabular}

$\mathrm{N}=2691$ (Except for ties formed where $\mathrm{N}=1,981$ because 1st wave has no observations.) 
Table A1.3: Pairwise correlation table

\begin{tabular}{|c|c|c|c|c|c|c|c|c|c|c|c|c|c|}
\hline & & 1 & 2 & 3 & 4 & 5 & 6 & 7 & 8 & 9 & 10 & 11 & 12 \\
\hline 1 & Tie formed & & & & & & & & & & & & \\
\hline 2 & Proximity & 0.102 & & & & & & & & & & & \\
\hline 3 & Peer within $1 \mathrm{~km}$ & 0.198 & 0.471 & & & & & & & & & & \\
\hline 4 & Peer within $2 \mathrm{~km}$ & 0.171 & 0.578 & 0.726 & & & & & & & & & \\
\hline 5 & Peer within $3 \mathrm{~km}$ & 0.126 & 0.692 & 0.501 & 0.690 & & & & & & & & \\
\hline 6 & Peer within $4 \mathrm{~km}$ & 0.112 & 0.761 & 0.389 & 0.536 & 0.777 & & & & & & & \\
\hline 7 & Management Practices Difference & 0.019 & -0.108 & -0.057 & -0.052 & -0.077 & -0.073 & & & & & & \\
\hline 8 & Marketing Practices Difference & -0.016 & 0.011 & -0.016 & 0.003 & 0.007 & 0.004 & 0.750 & & & & & \\
\hline 9 & Stock Practices Difference & -0.005 & -0.089 & -0.030 & -0.035 & -0.049 & -0.065 & 0.711 & 0.470 & & & & \\
\hline 10 & Planning Practices Difference & 0.041 & -0.096 & -0.007 & -0.004 & -0.048 & -0.061 & 0.779 & 0.465 & 0.598 & & & \\
\hline 11 & Financial Practices Difference & 0.032 & -0.133 & -0.092 & -0.092 & -0.107 & -0.087 & 0.707 & 0.320 & 0.292 & 0.334 & & \\
\hline 12 & Social skills training & -0.038 & -0.085 & -0.107 & -0.097 & -0.075 & -0.052 & 0.006 & 0.007 & -0.026 & 0.001 & 0.033 & \\
\hline 13 & Knew peer from before & 0.199 & 0.085 & 0.128 & 0.184 & 0.106 & 0.059 & -0.009 & -0.004 & 0.022 & 0.008 & -0.032 & 0.051 \\
\hline
\end{tabular}

$\mathrm{N}=2691$ (Except for ties formed where $\mathrm{N}=1,981$ because 1st wave has no observations.) 


\section{A2 Randomization and sample balance}

\section{Randomization}

During the networking event, entrepreneurs were randomized into three discussion pairs. The randomization into discussion peers was conducted at the end of the two day training program. The discussion partners were all from the same training cohort and the randomization was conducted while all participants were attending the marketing training. Therefore, all entrepreneurs randomly assigned were also treated, since none dropped out during the networking event. Discussions between entrepreneurs occurred one on one for about 30-45 minutes, after which entrepreneurs switched to their next discussion partner. The format of the networking event resembled the structure of a "speed dating" event.

Importantly, this randomization was orthogonal to the randomization of entrepreneurs into receiving social skills training, which happened at an earlier date and at a different level of analysis (that of the cohort). In the present study, we leverage the fact that there was natural variation in the spatial distance between entrepreneurs assigned to talk to each other. As a result, some entrepreneurs spoke with peers whose businesses happened to be located near them, while others spoke to entrepreneurs located at a greater distance. As shown in Table A2.1 the average proximity of discussion peers is unrelated to receiving the social skills training.

\section{Sample Balance}

Table A2.1 regresses observable entrepreneur characteristics on the average proximity of discussion partners. Each model from column 1 to 11 regresses proximity on a different characteristic, while models 12 and 13 include all entrepreneur characteristics. The table shows that, with the exception of Ewe ethnicity, the average proximity of assigned discussion partners is unrelated to the various characteristics of entrepreneurs. This suggests that the randomization was successful and that the average distance between discussion peers was not correlated with entrepreneurs' baseline levels (i.e. pre-treatment) of social networks, gender, age, management practices, employees, or performance.

In addition to the balance table (Table A2.1), we also show that along various dimensions, entrepreneurs in our sample were evenly distributed throughout the city. Figure A2.1 shows the spatial distribution of entrepreneur according to their baseline performance. According to this figure on average each neighborhood had a fair representation of performance levels. As a result, being assigned a distant or proximate peer likely does not correlate strongly with their performance level. Similarly, Figure A2.2 shows the spatial distribution of entrepreneurs along with their management practices at baseline. This figure also shows that, in general, each neighborhood contains a variety of levels of managerial best practices. This again suggests the distance of an assigned peer is likely to be unrelated to their baseline practices. Finally, Figure A2.3 plots the location of each entrepreneur and the industry their operate in. This figure shows that there is little geographic clustering of industries, which suggests that local neighborhoods are host to various diverse industries. 
Table A2.1: Balance of average peer proximity

\begin{tabular}{|c|c|c|c|c|c|c|c|c|c|c|c|c|c|}
\hline & (1) & (2) & (3) & (4) & (5) & (6) & (7) & (8) & (9) & (10) & (11) & (12) & (13) \\
\hline Peers known from before & $\begin{array}{l}0.003 \\
(0.015)\end{array}$ & & & & & & & & & & & $\begin{array}{l}0.007 \\
(0.014)\end{array}$ & $\begin{array}{l}0.007 \\
(0.014)\end{array}$ \\
\hline Social skills training & & $\begin{array}{l}-0.026 \\
(0.039)\end{array}$ & & & & & & & & & & $\begin{array}{l}-0.002 \\
(0.032)\end{array}$ & $\begin{array}{l}-0.003 \\
(0.032)\end{array}$ \\
\hline Ewe ethnicity & & & $\begin{array}{l}-0.050^{*} \\
(0.021)\end{array}$ & & & & & & & & & $\begin{array}{l}-0.039+ \\
(0.021)\end{array}$ & $\begin{array}{l}-0.038 \\
(0.022)\end{array}$ \\
\hline Female & & & & $\begin{array}{l}-0.003 \\
(0.023)\end{array}$ & & & & & & & & $\begin{array}{l}-0.005 \\
(0.020)\end{array}$ & $\begin{array}{l}-0.001 \\
(0.021)\end{array}$ \\
\hline Primary school completed & & & & & $\begin{array}{l}0.030 \\
(0.022)\end{array}$ & & & & & & & $\begin{array}{l}0.022 \\
(0.017)\end{array}$ & $\begin{array}{l}0.021 \\
(0.017)\end{array}$ \\
\hline Employees & & & & & & $\begin{array}{l}0.001 \\
(0.003)\end{array}$ & & & & & & $\begin{array}{l}0.003 \\
(0.003)\end{array}$ & $\begin{array}{l}0.003 \\
(0.003)\end{array}$ \\
\hline Firm age & & & & & & & $\begin{array}{l}-0.002 \\
(0.001)\end{array}$ & & & & & $\begin{array}{l}-0.000 \\
(0.001)\end{array}$ & $\begin{array}{l}-0.000 \\
(0.001)\end{array}$ \\
\hline Mgmt. practices score & & & & & & & & $\begin{array}{l}-0.067 \\
(0.051)\end{array}$ & & & & $\begin{array}{l}-0.047 \\
(0.048)\end{array}$ & $\begin{array}{l}-0.054 \\
(0.047)\end{array}$ \\
\hline Class size & & & & & & & & & $\begin{array}{l}-0.008 \\
(0.006)\end{array}$ & & & $\begin{array}{l}-0.008 \\
(0.005)\end{array}$ & $\begin{array}{l}-0.008 \\
(0.005)\end{array}$ \\
\hline Profits $(\log )$ & & & & & & & & & & $\begin{array}{l}-0.016 \\
(0.011)\end{array}$ & & $\begin{array}{l}-0.017 \\
(0.010)\end{array}$ & \\
\hline Performance index & & & & & & & & & & & $\begin{array}{c}-0.013 \\
(0.011)\end{array}$ & & $\begin{array}{l}-0.014 \\
(0.010)\end{array}$ \\
\hline$N$ & 274 & 274 & 274 & 274 & 274 & 274 & 274 & 274 & 274 & 274 & 274 & 274 & 274 \\
\hline
\end{tabular}

Note: Robust standard errors clustered by neighborhood in parentheses. $+p<0.10,{ }^{*} p<0.05$, $* * p<0.01$ 
Figure A2.1: Entrepreneur location and baseline profits

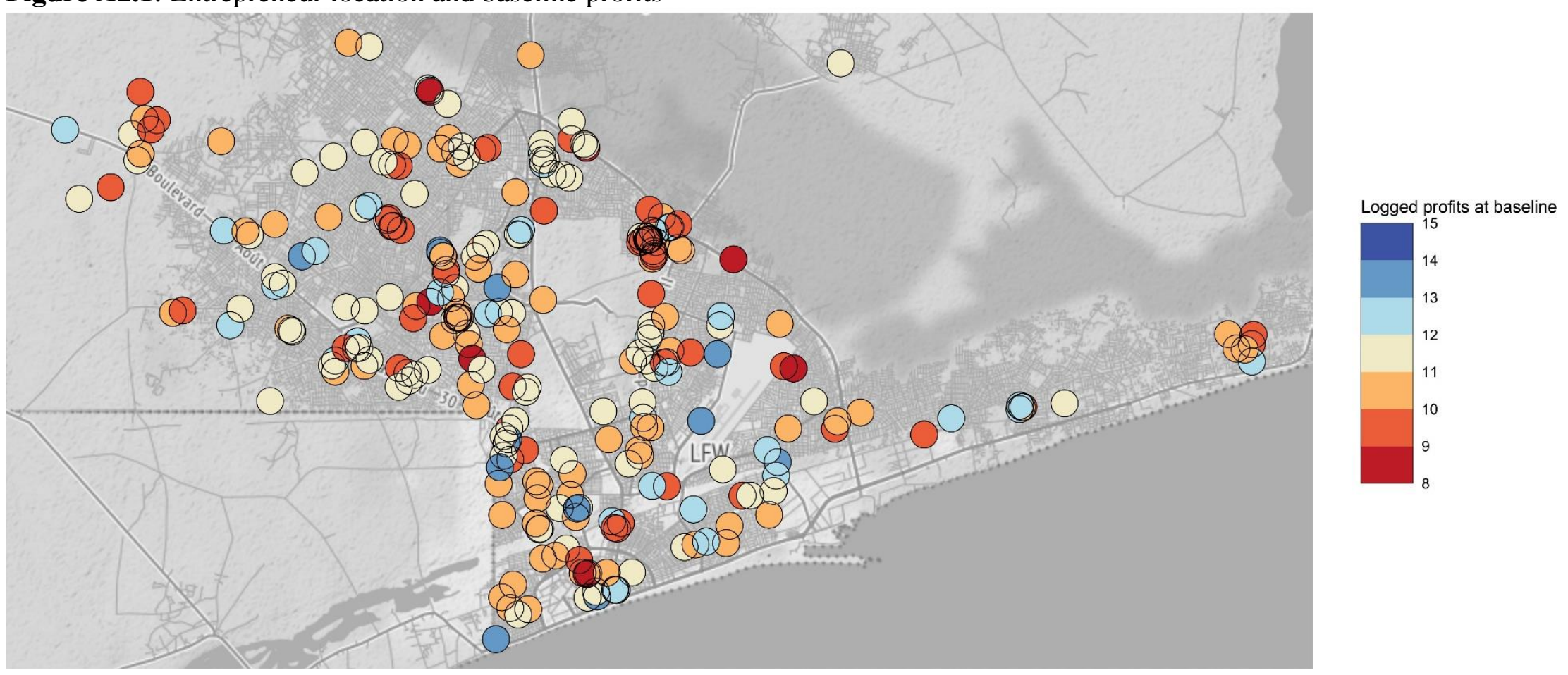

Note: This figure shows the approximate location of each entrepreneur in our sample with a circle. The coloring of the circle indicates entrepreneurs' log monthly profits at baseline, with blue shades representing high performance and red shades representing low performance. The distribution of colors in the plot suggests that although there is some clustering of entrepreneurs by performance, in general there is a significant amount of within-neighborhood variance in performance. 
Figure A2.2: Entrepreneurs' management practices at baseline

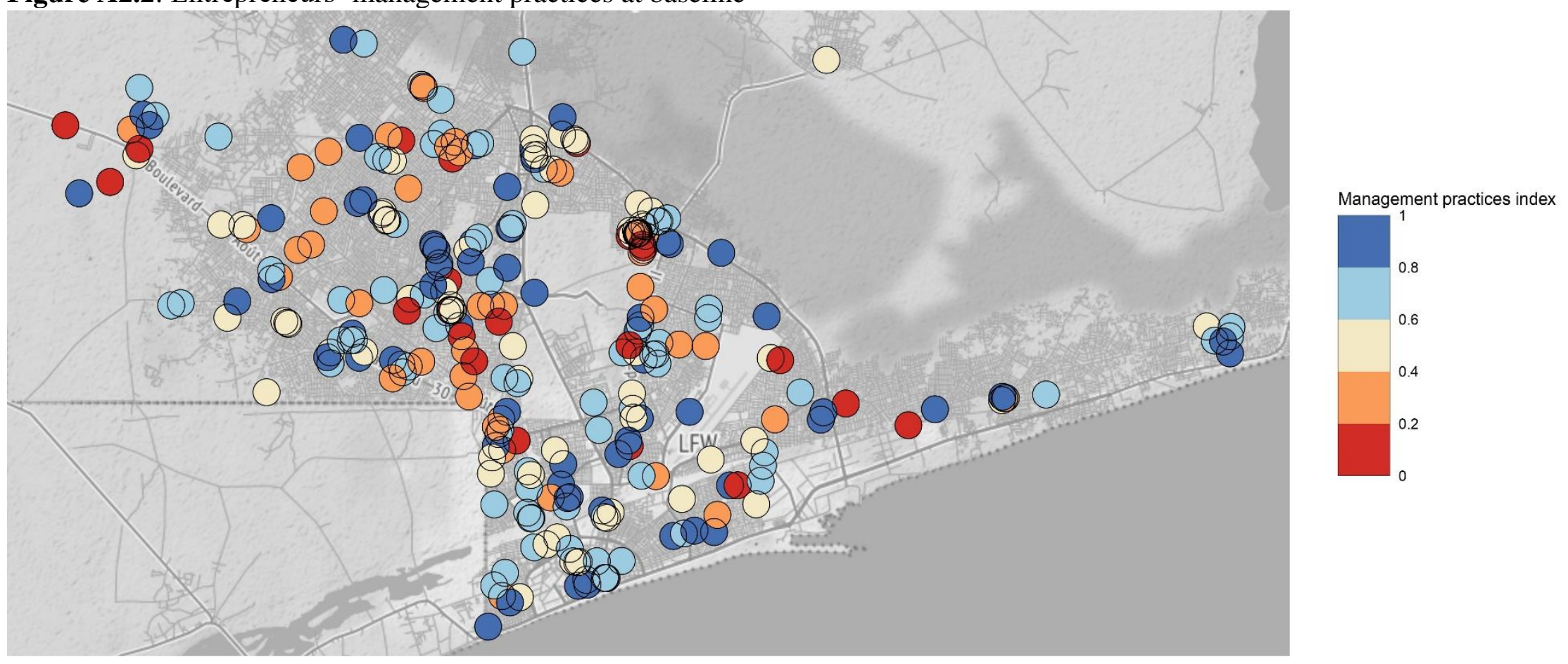

Note: This figure shows the approximate location of each entrepreneur in our sample. The coloring of circles represents entrepreneurs' management practices score, which is the proportion of management best practices described in McKenzie and Woodruff (2018) each entrepreneur uses. The pattern in the figure suggests that entrepreneurs with good management practices (blue colors) are broadly distributed throughout the city. Similarly, entrepreneurs without them (red colors) are also not confined to specific neighborhoods. 
Figure A2.3: Entrepreneurs' industry

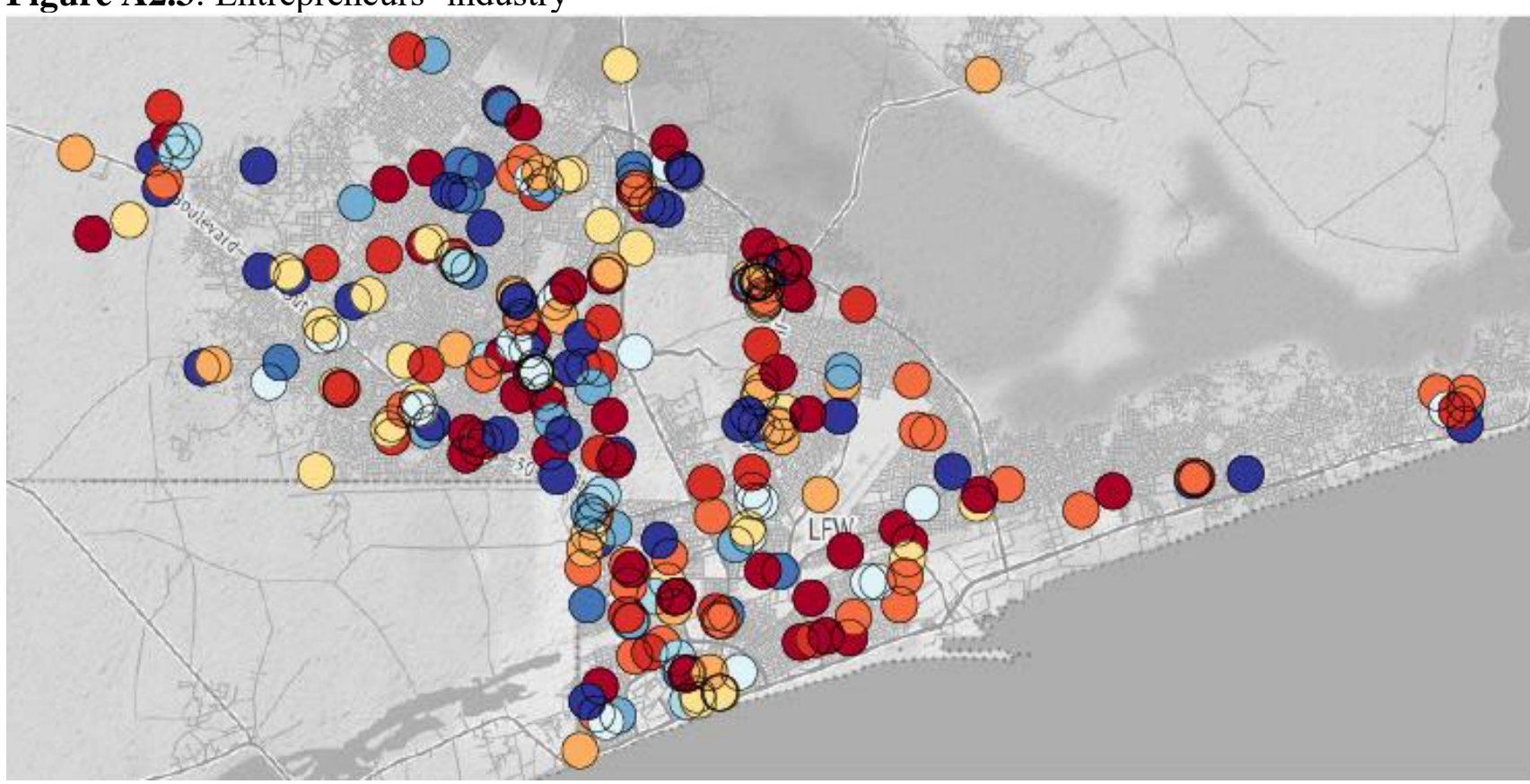

construction

Hairdressers

Internet, copying, and other text services Jewelry manuf photo and vid services sale of cereals, water, coal, and other product Sale of food or drink Tailoring, sewing, and shoemaking

various light manuf

various services

Note: This figure shows the approximate location of each entrepreneur in our sample with a circle. The coloring of the circle in this plot indicates the industry they belong to. The pattern of colors suggests that industries do not seem to cluster around certain areas. Instead, each color is represented throughout the various parts of the city. 


\section{Difference-in-Differences}

The empirical approach we use to estimate performance effects relies on difference-in-differences. In other words, it compares the change in performance for entrepreneurs assigned proximate peers, with the change in performance for entrepreneurs assigned more distant peers. This is illustrated graphically in Figure A2.4 below. The top panel plots the kernel density function of monthly profits $(\log )$ at baseline and 12 months later for entrepreneurs who were not assigned any peers within $3 \mathrm{~km}$. The bottom panel in Figure A2.4 plots the same thing for entrepreneurs who were assigned one or more peers within $3 \mathrm{~km}$, i.e. were treated. The figure therefore compares how much the performance changed over time for the control group entrepreneurs (no neighbor peers) to the change over time for treated entrepreneurs (assigned neighbors). The figure shows that for the control group the shift in the distribution of performance is smaller than the shift in performance for the treated group, which shifts considerably to the right.

Figure A2.4: Change in monthly profits (log) over time by control and treated groups
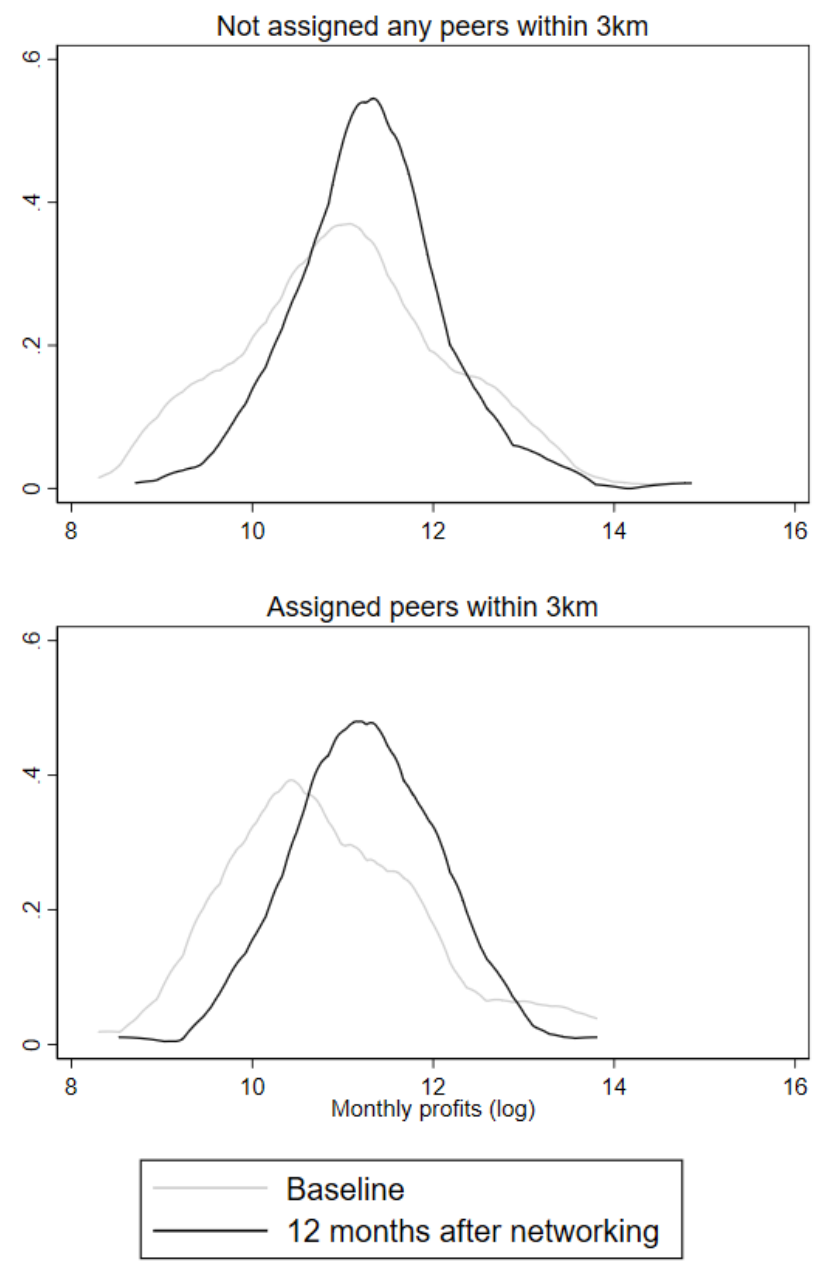

Note: This figure shows the distribution of log monthly profits for the control group and the treated group at baseline and 12 months after being matched with peers. The red dashed lines show the mean profits for each group at baseline and at 12 months. The distributions show that the average performance for the control group does not increase as much as the performance increases for the treated group. 


\section{A3 Results without inverse probability weights}

The regression models in the main paper include inverse propensity weights (IPWs) that account for potential bias introduced by the use of entrepreneur-level fixed effects, which nets out neighborhood effects. By inversely weighting observations by the probability of receiving the treatment we ensure that our estimates are not biased by differences between entrepreneurs in the odds of being treated.

To ensure, however, that our performance results are not dependent on using these IPWs we estimated the models in Table 2 from the paper without including any weights. The results are presented below in Table A3.1. According to Table A3.1, the statistical significance of our results remains largely unchanged. The most notable difference is that the magnitude of the coefficient for the continuous measure of treatment (average proximity) is about half.

Table A3.1: The impact of average peer proximity on performance

\begin{tabular}{|c|c|c|c|c|c|c|}
\hline & \multicolumn{5}{|c|}{ Monthly profits (log) } & \multirow{2}{*}{$\begin{array}{c}\text { Performance } \\
\text { Index } \\
(6)\end{array}$} \\
\hline & (1) & (2) & (3) & (4) & (5) & \\
\hline Post-Training X Ave. proximity & $\begin{array}{l}0.668^{*} \\
(0.283)\end{array}$ & & & & & $\begin{array}{l}0.494 * \\
(0.188)\end{array}$ \\
\hline Post-Training X Peers within $1 \mathrm{~km}$ & & $\begin{array}{c}0.245^{* *} \\
(0.068)\end{array}$ & & & & \\
\hline Post-Training X Peers within $2 \mathrm{~km}$ & & & $\begin{array}{c}0.190 * * \\
(0.062)\end{array}$ & & & \\
\hline Post-Training X Peers within $3 \mathrm{~km}$ & & & & $\begin{array}{c}0.105 \\
(0.066)\end{array}$ & & \\
\hline Post-Training X Peers within 4km & & & & & $\begin{array}{c}0.046 \\
(0.051)\end{array}$ & \\
\hline Entrepreneur FE & Yes & Yes & Yes & Yes & Yes & Yes \\
\hline Survey wave FE & Yes & Yes & Yes & Yes & Yes & Yes \\
\hline$N$ & 1033 & 1033 & 1033 & 1033 & 1033 & 1033 \\
\hline Entrepreneurs & 274 & 274 & 274 & 274 & 274 & 274 \\
\hline
\end{tabular}

Note: All models include interactions between the number of peers entrepreneurs knew from before the program and their social skills with the post-training indicator, as well as the indicator for post-training time periods. Robust standard errors clustered by entrepreneurs' neighborhood in parentheses

$+p<0.10, * p<0.05, * * p<0.01$ 


\section{A4 Removing entrepreneurs without any proximate peers}

In the main performance analyses for the paper we use both a continuous measure of treatment (average proximity) and a series of discrete measures of treatment. These discrete measures are the number of peers within different radii around the entrepreneur $(1 \mathrm{~km}, 2 \mathrm{~km}, 3 \mathrm{~km}$, and $4 \mathrm{~km})$. For some of these discrete measures there are entrepreneurs for whom the probability of being treated is zero. In other words, these entrepreneurs had no peers in their cohort who were located within the specified radius and hence there was no chance of them receiving the treatment. Although the inverse propensity score weights should account for this, we test the robustness of our results by excluding any entrepreneurs for whom the probability of being treated is zero in each of these discrete treatment measures.

Table A4.1 replicates the results from Models 2-5 in Table 2 from the main paper, after dropping entrepreneurs whose probability of being treated was zero. As the results show, the size of the effects and the statistical significance do not change substantially. Hence, our results are robust to this estimation approach.

Table A4.1: The impact of average peer proximity on performance

\section{(1)}

(2)

(3)

(4)

\begin{tabular}{lcccc} 
Post-Training X Peers within 1km & $\begin{array}{l}0.265^{*} \\
(0.131)\end{array}$ & & & \\
& & & \\
Post-Training X Peers within 2km & & $0.227^{*}$ & & \\
& & $(0.087)$ & & \\
& & & $0.156^{*}$ & \\
Post-Training X Peers within 3km & & & & \\
& & & & $0.074)$ \\
Post-Training X Peers within 4km & & & & \\
& & & & \\
& & & & \\
Entrepreneur FE & Yes & Yes & Yes & Yes \\
Survey wave FE & Yes & Yes & Yes & Yes \\
& & & & \\
\hline$N$ & 555 & 789 & 892 & 979 \\
Entrepreneurs & 146 & 209 & 237 & 260 \\
\hline
\end{tabular}

Note: Robust standard errors clustered by entrepreneurs' neighborhood in parentheses. Inverse probability weights included in all models. The number of entrepreneurs is less than 274 in each model because we drop those entrepreneurs who do not have any peers in their cohort within the specified radius $(1,2,3$, or $4 \mathrm{~km})$.

$+p<0.10, * p<0.05, * * p<0.01$ 


\section{A5 Modeling proximity with alternative decay functions}

To measure the performance effect of peer proximity we rely on a continuous measure of proximity. This measure is the average of each entrepreneurs' physical proximity to their discussion partners. The proximity between each pair of entrepreneurs is measured using an exponential distance decay function, described as Equation (1) in the paper. Although this approach to measuring the effect of distance is common (De Vries et al. 2009, Downey 2006, PunCheng 2016), there can be alternative ways of parameterizing proximity. To ensure that our results are not driven by the functional form of proximity, we also measured the proximity between each entrepreneur pairs using two alternative specifications.

The first alternative, which we label "Decay Function 1," uses the function $p_{i j}=d_{i j}^{-1.25}$ to calculate proximity. Where $d_{i j}$ is the distance in kilometers between entrepreneur $i$ and $j$. The second alternative function, which we label "Decay Function 2," is a simplified version Equation (1) in the paper: $p_{i j}=e^{-d_{i j}}$.

Table A5.1 reproduces Model 1 and Model 6 in Table 2 using these alternative functions for measuring proximity. As the regression results show, the magnitude of the performance effect is similar for both measures of performance as in Table 2 and the statistical significance remains unchanged.

Table A5.1: The impact of average peer proximity on performance

\begin{tabular}{|c|c|c|c|c|}
\hline & \multicolumn{2}{|c|}{ Decay Function 1} & \multicolumn{2}{|c|}{ Decay Function 2} \\
\hline & $\begin{array}{c}\text { Profits } \\
(\log )\end{array}$ & $\begin{array}{l}\text { Performance } \\
\text { Index }\end{array}$ & $\begin{array}{c}\text { Profits } \\
(\log )\end{array}$ & $\begin{array}{l}\text { Performance } \\
\text { Index }\end{array}$ \\
\hline & (1) & (2) & (3) & (4) \\
\hline Post-Training X Ave. proximity & $\begin{array}{c}0.118 * * \\
(0.035)\end{array}$ & $\begin{array}{c}0.098^{* *} \\
(0.030)\end{array}$ & $\begin{array}{c}1.077^{* *} \\
(0.381)\end{array}$ & $\begin{array}{c}0.571 * * \\
(0.179)\end{array}$ \\
\hline Entrepreneur FE & Yes & Yes & Yes & Yes \\
\hline Survey wave FE & Yes & Yes & Yes & Yes \\
\hline$N$ & 1033 & 1033 & 1033 & 1033 \\
\hline Entrepreneurs & 274 & 274 & 274 & 274 \\
\hline
\end{tabular}

Note: All models include interactions between the number of peers entrepreneurs knew from before the program and their social skills with the post-training indicator, as well as the post-training indicator itself. Inverse probability weights included in all models. Robust standard errors clustered by entrepreneurs' neighborhood in parentheses. $+\mathrm{p}<0.10,{ }^{*} \mathrm{p}<0.05, * * \mathrm{p}<0.01$ 


\section{A6 Temporal Dynamics}

Table 2 of the paper presents the performance effect of proximate discussion peers over the year after the training program (i.e. the post-training period). To provide more information about how the magnitude of this effect changes over time we show regressions that interact the proximity of assigned peers with each time period. The results are shown in Table A6.1. According to these results, there is a gradual increase in the performance effects over time, which aligns with the intuition that peers located near each other build relationships and continue to learn from each other over time. These results are depicted graphically in Figure 2 of the main paper.

Table 6.1: Temporal dynamics of average peer proximity on performance

\begin{tabular}{lcc}
\hline & $\begin{array}{c}\text { Monthly } \\
\text { Profits (log) }\end{array}$ & $\begin{array}{c}\text { Performance } \\
\text { Index }\end{array}$ \\
\hline & $(1)$ & $(2)$ \\
6 weeks after training X Ave. proximity & $0.968^{*}$ & $0.876^{*}$ \\
& $(0.367)$ & $(0.370)$ \\
6 months after training X Ave. proximity & $1.317^{*}$ & $1.276^{*}$ \\
& $(0.599)$ & $(0.497)$ \\
1 year after training X Ave. proximity & $1.428^{*}$ & $1.303^{*}$ \\
& $(0.652)$ & $(0.529)$ \\
Entrepreneur FE & & Yes \\
Survey wave FE & Yes & Yes \\
\hline$N$ & & 1033 \\
Entrepreneurs & 1033 & 274 \\
\hline
\end{tabular}

Note: All models include interactions between the number of peers entrepreneurs knew from before the program and their social skills with the post-training indicator. Inverse probability weights included in all models. Robust standard errors clustered by entrepreneurs' neighborhood in parentheses. $+\mathrm{p}<0.10, * \mathrm{p}<0.05$, ** $\mathrm{p}<0.01$ 


\section{A7 Additional measures of neighborhood embeddedness}

An additional indicator of entrepreneurs' embeddedness in their neighborhood is the number of years they have been located there. This variable captures the extent to which entrepreneurs have had a chance to engage with their neighbors. We would expect that the longer an entrepreneur has been located in a neighborhood the less benefit they will gain from meeting another neighbor. The reason for this being that they are more likely to already know many neighbors and be immersed in local knowledge networks.

To assess this we interact the number of years an entrepreneur has been in their neighborhood with the average proximity of their discussion partners. This is represented as a three-way interaction in Table 7.1. The coefficient for the three-way interaction is negative and statistically significant. The magnitude of this coefficient is larger than the magnitude of the interaction between posttraining and "years in neighborhood," which is positive. Hence, the overall effect is that the longer an entrepreneur has been located in a neighborhood the less they benefit from meeting more proximate peers. In other words, the benefits of peer proximity decrease with entrepreneurs' local embeddedness. The outcome in Model 1 is log monthly profits and in Model 2 it is the performance index. The effect is consistent across both performance outcomes. This three-way interaction is plotted in Figure 7.2, where the average impact of peer proximity on performance is estimated for each level of "years located in neighborhood." It is worth noting that at approximately 17 years the effect of peer proximity becomes statistically not significant, suggesting that perhaps those entrepreneurs tend to benefit more from meeting more distant peers.

Table A7.1: The impact of average peer proximity on performance

\begin{tabular}{|c|c|c|}
\hline & $\begin{array}{c}\text { Monthly } \\
\text { Profits (log) }\end{array}$ & $\begin{array}{l}\text { Performance } \\
\text { Index }\end{array}$ \\
\hline & $(1)$ & (2) \\
\hline Post-training X Ave. Proximity X Years in neighborhood & $\begin{array}{c}-0.116^{* *} \\
(0.027)\end{array}$ & $\begin{array}{c}-0.042 * * \\
(0.012)\end{array}$ \\
\hline Post-training X Years in neighborhood & $\begin{array}{c}0.064 * * \\
(0.016)\end{array}$ & $\begin{array}{l}0.020 * \\
(0.007)\end{array}$ \\
\hline Post-training X Ave. Proximity & $\begin{array}{c}2.465 * * \\
(0.588)\end{array}$ & $\begin{array}{l}1.097 * * \\
(0.289)\end{array}$ \\
\hline $\begin{array}{l}\text { Entrepreneur FE } \\
\text { Survey wave FE }\end{array}$ & $\begin{array}{l}\text { Yes } \\
\text { Yes }\end{array}$ & $\begin{array}{l}\text { Yes } \\
\text { Yes }\end{array}$ \\
\hline $\begin{array}{l}N \\
\text { Entrepreneurs }\end{array}$ & $\begin{array}{c}1033 \\
274 \\
\end{array}$ & $\begin{array}{c}1033 \\
274 \\
\end{array}$ \\
\hline
\end{tabular}

Note: All models include interactions between the number of peers entrepreneurs knew from before the program and their social skills with the post-training indicator. IPW included in all models. Robust standard errors clustered by entrepreneurs' neighborhood in parentheses. $+p<0.10, * p<0.05, * * p<0.01$ 
Figure 7.2: Average Marginal Effects of Ave. Proximity on Profits (log) with 95\% CIs

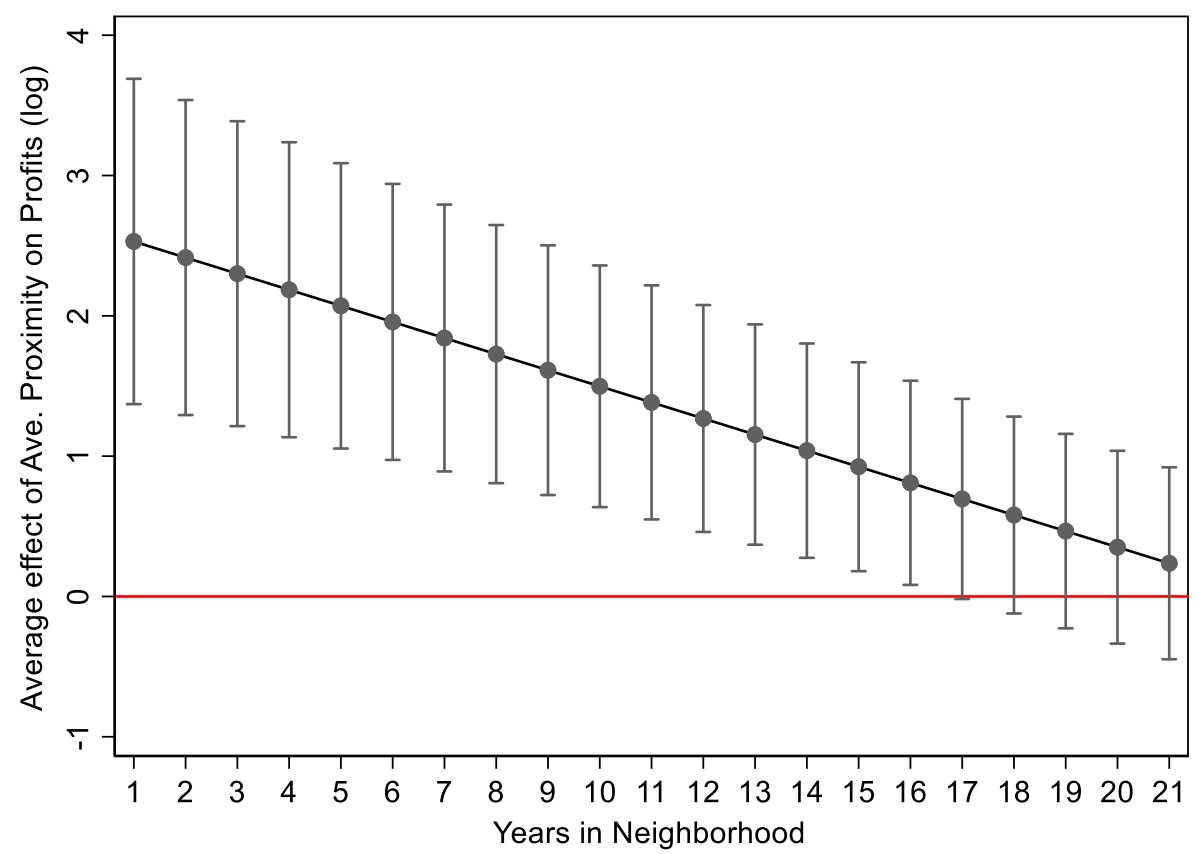

Note: This figure illustrates the three-way interaction in Model 1 Table A7.1 (in the Appendix) by plotting the estimated effect of proximity on profits for entrepreneurs with different tenures in their neighborhood. The pattern shows the diminishing effect of proximity-i.e. meeting a neighboron profits as the number of years the entrepreneur has been located in their neighborhood increases. 


\section{A8 Knowing peers before the training program}

Exploratory analyses suggest that most entrepreneurs in our sample tend not to be networked in their local neighborhoods, which explains why they tend to benefit from meeting local peers. Besides the years located in their neighborhood and local association membership, another way of gauging local embeddedness is exploring whether entrepreneurs are likely to know co-participants from their neighborhood. If entrepreneurs tend not to be locally networked, then we would expect them not to know entrepreneurs in their training cohort.

At the end of the training program we asked every entrepreneur whether they had known any of the other entrepreneurs in their cohort from before the program. Using a dyadic data structure, we regressed this indicator of knowing a peer from before on that peer's distance from the focal entrepreneur. The results from these regressions are shown in Table A8.1 below. The pattern in these coefficients is that the likelihood of an entrepreneur knowing a co-participant increases with proximity. However, despite the seemingly large size of the coefficients, the increase in likelihood of knowing a peer is relatively small as proximity increases. This suggests that in relative terms, most entrepreneurs were quite under networked.

Table 8.1: Probability of knowing peer from before the training

\begin{tabular}{lccccc}
\hline & \multicolumn{5}{c}{ Knew peer from before training } \\
\cline { 2 - 6 } & $(1)$ & $(2)$ & $(3)$ & $(4)$ & $(5)$ \\
\hline & & & & & \\
Ave. proximity & $1.697^{*}$ & & & & \\
& $(0.705)$ & & & & \\
Peer within 1km & & $1.130^{* *}$ & & & \\
& & $(0.345)$ & & & \\
Peer within 2km & & & $1.000^{* *}$ & & \\
& & & $(0.345)$ & & \\
Peer within 3km & & & & $0.904^{* *}$ & \\
& & & & $(0.317)$ & \\
Peer within 4km & & & & & $0.694^{*}$ \\
& & & & & \\
& 5326 & 5326 & 5326 & 5326 & 5326 \\
\hline$N$ & 274 & 274 & 274 & 274 & 274 \\
\hline Entrepreneurs & & &
\end{tabular}

Note: All models logit. Only baseline period included. All models control for entrepreneur social skills. Robust standard errors clustered by neighborhood in parentheses.

$+p<0.10, * p<0.05, * * p<0.01$ 


\section{A9 Similarity between entrepreneurs and peers in managerial knowledge}

For each pair of entrepreneurs in a training cohort, we calculated the similarity between their management practices. We used the index of 27 best practices developed by McKenzie and Woodruff (2018). For each of the practices, entrepreneurs responded whether they used it or not at baseline. These 27 practices are grouped into practices related to marketing, stock management, planning, and finances. For the total management score and each category of practices separately, we calculated the similarity in practices between entrepreneurs as "1-Euclidean distance in practices." Where the Euclidean distance in practices is the difference in vectors of management practices between the entrepreneurs.

The results of regressing practice similarity on the physical proximity between any two entrepreneurs is shown in Table A9.1. Note that this relies on dyad-level data, where the dyad is every pair of entrepreneurs in a training cohort. The results indicate that there is no overall pattern of having more similar practices as entrepreneurs are located more closely together. Although in some cases, such as planning practices and financial practices, entrepreneurs near each other may have more similar knowledge.

Table A9.1: The effect of proximity on the difference in management practices between peers

\begin{tabular}{lccccc}
\hline & $\begin{array}{c}\text { Total } \\
\text { Management } \\
\text { Practices } \\
\text { Similarity }\end{array}$ & $\begin{array}{c}\text { Marketing } \\
\text { Practices } \\
\text { Similarity }\end{array}$ & $\begin{array}{c}\text { Stocking } \\
\text { Practices } \\
\text { Similarity }\end{array}$ & $\begin{array}{c}\text { Planning } \\
\text { Practices } \\
\text { Similarity }\end{array}$ & $\begin{array}{c}\text { Financial } \\
\text { Practices } \\
\text { Similarity }\end{array}$ \\
\cline { 2 - 6 } Proximity & $(1)$ & $(2)$ & $(3)$ & $(4)$ & $(5)$ \\
& 0.726 & $-0.285+$ & -0.016 & $0.355^{*}$ & $0.557^{* *}$ \\
& $(0.461)$ & $(0.158)$ & $(0.167)$ & $(0.155)$ & $(0.178)$ \\
\hline$N$ & 5326 & 5326 & 5326 & 5326 & 5326 \\
Entrepreneurs & 274 & 274 & 274 & 274 & 274 \\
\hline
\end{tabular}

Note: Robust standard errors clustered by ego, alter, and dyad in parentheses. All models control for social skills and whether the peers knew each other form before training.

$+p<0.10, * p<0.05, * * p<0.01$ 


\section{A10 Dyad Performance Regressions}

Another approach to measuring performance is to rely on the dyad-level data. In this approach, the unit of analysis is any pair of entrepreneurs who were assigned as discussion partners. We regress the performance of each focal entrepreneur on their distance from their matched peer. We include ego-entrepreneur fixed effects, matched-entrepreneur fixed effects, dyad fixed effects, and survey wave fixed effects. All models also control for entrepreneurs' social skills and whether the pair had ever met before the training program.

The results are shown in Table A10.1 below. The pattern of effects is very similar to those in our main performance table (Table 2 in the paper). Hence, this alternative empirical strategy replicates our main performance findings.

Table A10.1: The impact of average peer proximity on performance using dyad-level data

Monthly Profits $(\log )$

Performance Index

(1) $0.452 * *$

$(0.142)$

(3)

(4)

(5)

\begin{tabular}{|c|c|c|c|c|c|c|}
\hline Post-Training X Proximity & $\begin{array}{c}0.452 * * \\
(0.142)\end{array}$ & & & & & $\begin{array}{c}0.336 * * \\
(0.116)\end{array}$ \\
\hline Post-Training X Peer within $1 \mathrm{~km}$ & & $\begin{array}{c}0.323 * * \\
(0.106)\end{array}$ & & & & \\
\hline Post-Training X Peer within $2 \mathrm{~km}$ & & & $\begin{array}{c}0.268 * * \\
(0.081)\end{array}$ & & & \\
\hline Post-Training X Peer within $3 \mathrm{~km}$ & & & & $\begin{array}{l}0.165^{*} \\
(0.074)\end{array}$ & & \\
\hline Post-Training X Peer within $4 \mathrm{~km}$ & & & & & $\begin{array}{c}0.093 \\
(0.068)\end{array}$ & \\
\hline Ego FE & Yes & Yes & Yes & Yes & Yes & Yes \\
\hline Alter FE & Yes & Yes & Yes & Yes & Yes & Yes \\
\hline Dyad FE & Yes & Yes & Yes & Yes & Yes & Yes \\
\hline Survey wave FE & Yes & Yes & Yes & Yes & Yes & Yes \\
\hline$N$ & 2690 & 2690 & 2690 & 2690 & 2690 & 2690 \\
\hline Entrepreneurs & 274 & 274 & 274 & 274 & 274 & 274 \\
\hline
\end{tabular}

Note: Robust standard errors clustered by ego, alter, and dyad. All models control for entrepreneur social skills and whether the peer was known from before.

$+p<0.10, * p<0.05, * * p<0.01$ 


\section{A11 Performance results with different control variable configurations}

\section{No control variables}

To ensure that the results are not sensitive to the controls for social skills or the control for number of peers known from before the training program we estimate the main performance models excluding these two control variables. The results are shown in Table A11.1 below. The substantive interpretation of the coefficients is largely the same as when the control variables are included.

Table A11.1: The impact of average peer proximity on performance without any control variables

\section{(1)}

(2)

(3)

(4)

(5)

(6)

Post-Training X Ave. proximity

Post-Training X Peers within $1 \mathrm{~km}$

Post-Training X Peers within $2 \mathrm{~km}$

Post-Training X Peers within $3 \mathrm{~km}$

Post-Training X Peers within 4km

Entrepreneur FE

Survey wave FE
$1.178 *$

(0.564)

$0.309 * *$

(0.104)
(0.081)

0.152

(0.094)

$1.259 *$

$\begin{array}{rr}(0.104) & \\ & 0.234 * * \\ & (0.081)\end{array}$

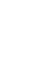

(0.510)

\begin{tabular}{lcccccc}
\hline$N$ & 1033 & 1033 & 1033 & 1037 & 1037 & 1033 \\
Entrepreneurs & 274 & 274 & 274 & 274 & 274 & 274 \\
\hline
\end{tabular}

Note: Inverse propensity score weights included in all models. Robust standard errors clustered by entrepreneurs' neighborhood in parentheses.

$+p<0.10, * p<0.05, * * p<0.01$ 


\section{Performance effects with additional control variables}

Given that our results hold with few or no control variables, we also wanted to ensure that they are robust to various controls for entrepreneur and peer characteristics - even though that is not our preferred estimation approach (for a justification please see the section "Estimation strategy" in the main paper). We therefore estimated our performance models control for entrepreneurs' management practices, size of business, ethnicity, gender, education, and firm age. Those controls that do not vary with time were interacted with the "Post-Training" time indicator. Table A11.2 shows the results after including these control variables. At the results show, there is little change in the magnitude or statistical significance of the coefficients. The except is Model 4, where the coefficient of interest becomes marginally less statistically significant, although the magnitude is very similar to that in Table 2 .

Table A11.2: The impact of average peer proximity on performance including added controls

\begin{tabular}{|c|c|c|c|c|c|c|}
\hline & \multicolumn{5}{|c|}{ Monthly Profits (log) } & \multirow{2}{*}{$\begin{array}{c}\begin{array}{c}\text { Performance } \\
\text { Index }\end{array} \\
(6)\end{array}$} \\
\hline & (1) & (2) & (3) & (4) & (5) & \\
\hline Post-Training X Ave. proximity & $\begin{array}{l}1.316^{*} \\
(0.609)\end{array}$ & & & & & $\begin{array}{l}1.214^{*} \\
(0.506)\end{array}$ \\
\hline Post-Training X Peers within $1 \mathrm{~km}$ & & $\begin{array}{l}0.288^{*} \\
(0.114)\end{array}$ & & & & \\
\hline Post-Training X Peers within $2 \mathrm{~km}$ & & & $\begin{array}{l}0.179 * \\
(0.079)\end{array}$ & & & \\
\hline Post-Training X Peers within 3km & & & & $\begin{array}{c}0.127 \\
(0.087)\end{array}$ & & \\
\hline Post-Training X Peers within 4km & & & & & $\begin{array}{c}0.037 \\
(0.050)\end{array}$ & \\
\hline Management practice score & $\begin{array}{c}0.478 * * \\
(0.133)\end{array}$ & $\begin{array}{c}0.519^{* * *} \\
(0.172)\end{array}$ & $\begin{array}{c}0.593 * * \\
(0.162)\end{array}$ & $\begin{array}{c}0.567 * * \\
(0.156)\end{array}$ & $\begin{array}{c}0.543 * * \\
(0.163)\end{array}$ & $\begin{array}{c}0.375 * * \\
(0.084)\end{array}$ \\
\hline Employees & $\begin{array}{c}0.014 \\
(0.018)\end{array}$ & $\begin{array}{c}0.023 \\
(0.018)\end{array}$ & $\begin{array}{c}0.021 \\
(0.019)\end{array}$ & $\begin{array}{c}0.024 \\
(0.021)\end{array}$ & $\begin{array}{c}0.013 \\
(0.018)\end{array}$ & $\begin{array}{c}0.023 \\
(0.019)\end{array}$ \\
\hline Ewe ethnicity X Post-training & $\begin{array}{c}0.173 \\
(0.115)\end{array}$ & $\begin{array}{l}0.213+ \\
(0.127)\end{array}$ & $\begin{array}{c}0.166 \\
(0.114)\end{array}$ & $\begin{array}{c}0.132 \\
(0.126)\end{array}$ & $\begin{array}{c}0.089 \\
(0.096)\end{array}$ & $\begin{array}{c}0.088 \\
(0.090)\end{array}$ \\
\hline Female X Post-training & $\begin{array}{l}0.180+ \\
(0.105)\end{array}$ & $\begin{array}{c}0.256^{* * *} \\
(0.088)\end{array}$ & $\begin{array}{l}0.204 * \\
(0.095)\end{array}$ & $\begin{array}{l}0.276^{*} \\
(0.113)\end{array}$ & $\begin{array}{l}0.202^{*} \\
(0.078)\end{array}$ & $\begin{array}{c}0.119 \\
(0.103)\end{array}$ \\
\hline Primary School X Post-training & $\begin{array}{l}-0.251+ \\
(0.140)\end{array}$ & $\begin{array}{c}-0.307 * * \\
(0.098)\end{array}$ & $\begin{array}{c}-0.261 * \\
(0.106)\end{array}$ & $\begin{array}{c}-0.286+ \\
(0.160)\end{array}$ & $\begin{array}{c}-0.240 * * \\
(0.080)\end{array}$ & $\begin{array}{l}-0.184 \\
(0.146)\end{array}$ \\
\hline Firm age $\mathrm{X}$ Post-training & $\begin{array}{l}-0.013 \\
(0.009)\end{array}$ & $\begin{array}{l}-0.015^{*} \\
(0.007)\end{array}$ & $\begin{array}{l}-0.010 \\
(0.008)\end{array}$ & $\begin{array}{l}-0.016 \\
(0.010)\end{array}$ & $\begin{array}{c}-0.008 \\
(0.006)\end{array}$ & $\begin{array}{l}-0.014 \\
(0.009)\end{array}$ \\
\hline Entrepreneur FE & Yes & Yes & Yes & Yes & Yes & Yes \\
\hline Survey wave FE & Yes & Yes & Yes & Yes & Yes & Yes \\
\hline$N$ & 1033 & 1033 & 1033 & 1033 & 1033 & 1033 \\
\hline Entrepreneurs & 274 & 274 & 274 & 274 & 274 & 274 \\
\hline
\end{tabular}

Note: Robust standard errors clustered by entrepreneurs' neighborhood in parentheses. IPW included.

$+p<0.10, * p<0.05, * * p<0.01$ 
In addition to control for entrepreneur characteristics, we also estimated models including peer characteristics. We averaged the assigned peers' firm age, size, and management practices. We also controlled for the number of peers who shared the same gender and same industry as the focal entrepreneur. All of these controls are time invariant and we therefore interacted them with the Post-Training binary variable. Results are shown in Table A11.3. As these indicate, the results are robust to the inclusion of these additional control variables.

Table A11.3: The impact of average peer proximity on performance including ego and peer controls

\begin{tabular}{|c|c|c|c|c|c|c|}
\hline & \multicolumn{5}{|c|}{ Profits } & \multirow{2}{*}{$\begin{array}{c}\text { Performance } \\
\text { Index }\end{array}$} \\
\hline & $(1)$ & $(2)$ & $(3)$ & $(4)$ & $(5)$ & \\
\hline Post-Training X Ave. proximity & $\begin{array}{l}1.246 * \\
(0.516)\end{array}$ & & & & & $\begin{array}{c}1.082 * * \\
(0.389)\end{array}$ \\
\hline Post-Training X Peers within $1 \mathrm{~km}$ & & $\begin{array}{c}0.288 * * \\
(0.105)\end{array}$ & & & & \\
\hline Post-Training X Peers within $2 \mathrm{~km}$ & & & $\begin{array}{l}0.171 * \\
(0.077)\end{array}$ & & & \\
\hline Post-Training X Peers within $3 \mathrm{~km}$ & & & & $\begin{array}{c}0.112 \\
(0.081)\end{array}$ & & \\
\hline Post-Training X Peers within $4 \mathrm{~km}$ & & & & & $\begin{array}{c}0.037 \\
(0.048)\end{array}$ & \\
\hline Management practice score & $\begin{array}{c}0.512 * * \\
(0.161)\end{array}$ & $\begin{array}{c}0.579 * * \\
(0.185)\end{array}$ & $\begin{array}{c}0.661 * * \\
(0.179)\end{array}$ & $\begin{array}{c}0.627 * * \\
(0.169)\end{array}$ & $\begin{array}{c}0.554 * * \\
(0.174)\end{array}$ & $\begin{array}{c}0.407 * * \\
(0.105)\end{array}$ \\
\hline Employees & $\begin{array}{c}0.012 \\
(0.023)\end{array}$ & $\begin{array}{c}0.029 \\
(0.021)\end{array}$ & $\begin{array}{c}0.025 \\
(0.021)\end{array}$ & $\begin{array}{c}0.028 \\
(0.022)\end{array}$ & $\begin{array}{c}0.014 \\
(0.020)\end{array}$ & $\begin{array}{c}0.020 \\
(0.022)\end{array}$ \\
\hline Ewe ethnicity X Post-training & $\begin{array}{c}0.185 \\
(0.121)\end{array}$ & $\begin{array}{c}0.192 \\
(0.121)\end{array}$ & $\begin{array}{c}0.156 \\
(0.109)\end{array}$ & $\begin{array}{c}0.134 \\
(0.125)\end{array}$ & $\begin{array}{c}0.087 \\
(0.094)\end{array}$ & $\begin{array}{c}0.088 \\
(0.097)\end{array}$ \\
\hline Female X Post-training & $\begin{array}{c}0.099 \\
(0.093)\end{array}$ & $\begin{array}{c}0.227 * * \\
(0.080)\end{array}$ & $\begin{array}{l}0.184 * \\
(0.085)\end{array}$ & $\begin{array}{l}0.249 * \\
(0.114)\end{array}$ & $\begin{array}{l}0.177 * \\
(0.080)\end{array}$ & $\begin{array}{c}0.018 \\
(0.072)\end{array}$ \\
\hline Primary School X Post-training & $\begin{array}{c}-0.267^{*} \\
(0.123)\end{array}$ & $\begin{array}{c}-0.280 * * \\
(0.086)\end{array}$ & $\begin{array}{c}-0.234^{*} \\
(0.100)\end{array}$ & $\begin{array}{c}-0.260+ \\
(0.141)\end{array}$ & $\begin{array}{c}-0.239 * * \\
(0.081)\end{array}$ & $\begin{array}{c}-0.202+ \\
(0.113)\end{array}$ \\
\hline Firm age $\mathrm{X}$ Post-training & $\begin{array}{l}-0.015 \\
(0.010)\end{array}$ & $\begin{array}{c}-0.016+ \\
(0.009)\end{array}$ & $\begin{array}{l}-0.012 \\
(0.009)\end{array}$ & $\begin{array}{l}-0.018 \\
(0.011)\end{array}$ & $\begin{array}{l}-0.008 \\
(0.007)\end{array}$ & $\begin{array}{c}-0.018+ \\
(0.009)\end{array}$ \\
\hline Ave. Peer Industry Homophily X Post-training & $\begin{array}{l}-0.037 \\
(0.220)\end{array}$ & $\begin{array}{l}0.339+ \\
(0.197)\end{array}$ & $\begin{array}{c}0.249 \\
(0.188)\end{array}$ & $\begin{array}{c}0.294 \\
(0.252)\end{array}$ & $\begin{array}{c}0.128 \\
(0.179)\end{array}$ & $\begin{array}{c}0.024 \\
(0.210)\end{array}$ \\
\hline Ave. Peer Gender Homophily X Post-training & $\begin{array}{l}-0.276 \\
(0.223)\end{array}$ & $\begin{array}{l}-0.007 \\
(0.163)\end{array}$ & $\begin{array}{l}-0.000 \\
(0.172)\end{array}$ & $\begin{array}{c}-0.041 \\
(0.212)\end{array}$ & $\begin{array}{c}-0.062 \\
(0.157)\end{array}$ & $\begin{array}{c}-0.293+ \\
(0.173)\end{array}$ \\
\hline Ave. Peer Management Practices Score X Post-training & $\begin{array}{c}0.627 \\
(0.574)\end{array}$ & $\begin{array}{c}0.485 \\
(0.409)\end{array}$ & $\begin{array}{c}0.492 \\
(0.407)\end{array}$ & $\begin{array}{c}0.495 \\
(0.628)\end{array}$ & $\begin{array}{c}0.093 \\
(0.309)\end{array}$ & $\begin{array}{c}0.955 \\
(0.578)\end{array}$ \\
\hline Ave. Peer Firm Age X Post-training & $\begin{array}{c}0.000 \\
(0.001)\end{array}$ & $\begin{array}{l}-0.000 \\
(0.001)\end{array}$ & $\begin{array}{l}-0.000 \\
(0.001)\end{array}$ & $\begin{array}{c}0.000 \\
(0.001)\end{array}$ & $\begin{array}{l}-0.000 \\
(0.000)\end{array}$ & $\begin{array}{c}0.001 \\
(0.001)\end{array}$ \\
\hline Ave. Peer Employees X Post-training & $\begin{array}{c}-0.020 \\
(0.054)\end{array}$ & $\begin{array}{c}0.008 \\
(0.047)\end{array}$ & $\begin{array}{c}0.012 \\
(0.046)\end{array}$ & $\begin{array}{c}0.009 \\
(0.044)\end{array}$ & $\begin{array}{c}0.002 \\
(0.046)\end{array}$ & $\begin{array}{c}-0.049 \\
(0.036)\end{array}$ \\
\hline Entrepreneur FE & Yes & Yes & Yes & Yes & Yes & Yes \\
\hline Survey wave FE & Yes & Yes & Yes & Yes & Yes & Yes \\
\hline$N$ & 1033 & 1033 & 1033 & 1033 & 1033 & 1033 \\
\hline Entrepreneurs & 274 & 274 & 274 & 274 & 274 & 274 \\
\hline
\end{tabular}




\section{A12 Are proximate peers likelier to become clients, suppliers, or provide referrals}

A potential reason why peers who are located physically closer to the focal entrepreneur may be more useful is that they are likelier to become clients, suppliers, or make referrals. At the end of the networking event we asked each entrepreneur to fill out an exit survey about their discussions during the event. The survey asked entrepreneurs whether each of their assigned discussion partners could become a client or supplier. The survey also asked whether their discussion partner had provided them with a referral or was going to provide them with one in the near future.

Using the dyadic level data, where the dyad is the discussion pair, we regressed each of these outcomes on our measure of peer proximity. The results are shown in Table A12.1. In each case, proximity is not predictive of the discussion peer being a potential client or supplier, or of offering referrals. These results speak to the kinds of information exchanged between peers during these discussions. It doesn't seem that neighbors were more likely to be potential clients or suppliers than peers who were located further away. Similarly, neighbors don't seem to have been likelier to become a source of referrals. This suggests that proximate peers were valuable for other reasons, for providing access to other kinds of information - likely related to managerial practices.

Table A12.1: Proximity and Finding Suppliers, Clients, and Referrals

\begin{tabular}{lccc}
\hline & $\begin{array}{c}\text { Potential } \\
\text { client }\end{array}$ & $\begin{array}{c}\text { Potential } \\
\text { supplier }\end{array}$ & Got a referral \\
\cline { 2 - 4 } & $(1)$ & $(2)$ & $(3)$ \\
\hline & & & \\
Peer proximity & 0.581 & -0.133 & 0.410 \\
& $(0.491)$ & $(0.389)$ & $(0.465)$ \\
\hline$N$ & 710 & 710 & 710 \\
Entrepreneurs & 274 & 274 & 274 \\
\hline
\end{tabular}

Note: Robust standard errors clustered by ego, alter, and dyad in parentheses. All models control for social skills treatment and whether the peer was known from before the training. $+p<0.10, * p<0.05, * * p<0.01$ 


\section{A13 Minimum detectable effect size and power calculations}

The randomization we rely on was not conducted with the specific intention of testing the impact of peer proximity on entrepreneur performance. Rather, we used it as a natural experiment to gain exogenous variation on extent to which entrepreneurs met proximate peers. Given this, ex ante power calculations were not done and it is therefore instructive and a good precaution to calculate the minimum detectable effect (MDE) size, which would help ensure that our sample size is sufficient to detect the effects that we find.

A prior study that involved the randomization of entrepreneurs into discussion pairs is Chatterji et al. (2019). In this study, 100 early stage startup founders were randomized into pairs during a 3 day executive retreat. Using a difference-in-differences specification similar to that used in this study, the authors find that being matched with an entrepreneur who is a better manager leads to increases in sales and startup size two years after the retreat. Given that this closely related study reported 95\% power for detecting their performance effect, we expect that our sample of 274 should be sufficient to detect changes in performance.

Following Burlig et al. (2020), we estimate the MDE using the Stata program "pd_dd_analytic," which accounts for the panel structure of the data. This approach uses the residual standard deviation of the dependent variable (log monthly profits) after partialing out unit and time period fixed effects, to allow for non-constant serial correlation.

Our sample consists of 274 firms, the auto-correlation in log monthly profits is 0.62 , the raw standard deviation for $\log$ monthly profits is 0.99 , and after accounting for firm and time-period fixed effects the residual standard deviation is 0.53 . Based on these statistics, the MDE for our continuous treatment variable (average peer proximity) is 0.168. Table A13.1 shows the MDE for the categorical treatment variables, each of which defines treatment as having at least one or more peers within a given radius. The MDEs for these treatment variables range from 0.16 to 0.24 . All of these effect sizes are in the range of what McKenzie (2021) reports for training programs relying on peer and mentorship feedback, which tend to have effects of about 15\% [95\% CI:8\%, 22\%].

Table A13.1: MDE by treatment variable

\begin{tabular}{|c|c|c|c|}
\hline Radius (Treatment) & Proportion Treated & Power & MDE \\
\hline $1 \mathrm{~km}$ & $14 \%$ & 0.8 & 0.24 \\
\hline $2 \mathrm{~km}$ & $27 \%$ & 0.8 & 0.19 \\
\hline $3 \mathrm{~km}$ & $50 \%$ & 0.8 & 0.16 \\
\hline $4 \mathrm{~km}$ & $75 \%$ & 0.8 & 0.19 \\
\hline
\end{tabular}

The performance effects we report in Table 2 of the paper range from 0.140 to 1.247. Although we caution about overinterpreting the MDE (since it relies on ex post calculations), it appears that our study is adequately powered to detect most of our critical results. In particular, the estimates for our continuous measures of proximity range from 1.162 to 1.247 , which is far above the MDE. The effect size for treatments based on radii are larger than the MDE at radii of $1 \mathrm{~km}$ and $2 \mathrm{~km}$. The MDE for radius of $3 \mathrm{~km}$ is approximately the same as the magnitude estimated in the regression. 
These power calculations reveal that we are not adequately powered to detect performance effects for measures of peer proximity that rely on radii greater than $3 \mathrm{~km}$. For these measures, the effect sizes are such that we cannot reliably reject the null hypothesis. Hence, for peers located further than $3 \mathrm{~km}$ from the focal entrepreneur it isn't clear whether their performance effect is null or whether we simply do not have enough data to measure them precisely enough.

\section{REFERENCES}

Burlig F, Preonas L, Woerman M (2020) Panel data and experimental design. J. Devel. Econ. 144 102458.

Chatterji A, Delecourt S, Hasan S, Koning RM (2019) When does advice impact startup performance? Strateg. Manage. J. 40(3): 331-356.

De Vries JJ, Nijkamp P, Rietveld P (2009) Exponential or power distance-decay for commuting? An alternative specification. Environment and Planning 41(2): 461-480.

Downey L (2006) Environmental racial inequality in detroit. Soc. Forces 85(2): 771-796.

McKenzie D (2021) Small business training to improve management practices in developing countries: Re-assessing the evidence for 'training doesn't work'. Oxford Rev. Econ. Pol. 37(2): 276-301.

McKenzie D, Woodruff C (2018) Business practices in small firms in developing countries. Manage. Sci. 63(9): 2967-2981.

Pun-Cheng LS. 2016. Distance decay. John Wiley \& Sons, Hoboken, NJ.

World Bank. 2016. Country highlights togo. World Bank Group, Washington, D.C.

World Bank. 2019. Togo: Future sources of growth. Finance Competitiveness and Innovation Africa Region, Washington, D.C. 
